\title{
Model-based comparison of sequencing batch reactors and continuous-flow activated sludge processes for biological wastewater treatment
}

\author{
Jenifer Benavides Sanchez, ${ }^{a}$ Marianna Vuono, ${ }^{a, b}$ Davide Dionis $i^{{ }^{*}}$ \\ aMaterials and Chemical Engineering Group, School of Engineering, University of Aberdeen, \\ Aberdeen, AB24 3UE, UK \\ ${ }^{b}$ Department of Civil, Chemical, Environmental, and Materials Engineering, University of \\ Bologna, Bologna, Italy
}

\begin{abstract}
This study compares, based on mathematical modelling, continuous-flow activated sludge processes (CAS) and sequencing batch reactors (SBR). The steady-state or periodic steady-state of CAS and SBR processes is compared for a feed composed of readily or slowly biodegradable substrates, for carbon and for carbon and nitrogen removal. The simulations are carried out for different values of the SRT (solids residence time), HRT (hydraulic residence time), number of cycles and internal recycle. If the SRT is large enough, the SBR can remove the influent biodegradable COD completely, while the CAS has a residual effluent COD concentration. For carbon and nitrogen removal, the SBR can remove the ammonia completely while the CAS has a residual effluent ammonia concentration. For typical values of the operating parameters, the CAS gives higher total nitrogen removal than the SBR, which becomes comparable to the CAS only for a large number of cycles per day.

Keywords: wastewater treatment, activated sludge, sequencing batch reactor, modelling.

* email: davidedionisi@abdn.ac.uk, phone: +44 (0)1224 272814
\end{abstract}




\section{Nomenclature}

\begin{tabular}{|c|c|c|}
\hline Name & Description & Unit \\
\hline AerFill & Aerobic fill phase (SBR) & \\
\hline AnoxFill & Anoxic fill phase (SBR) & \\
\hline b & Kinetic parameter (endogenous metabolism, heterotrophic biomass) & $d^{-1}$ \\
\hline $\mathrm{b}_{\mathrm{A}}$ & Kinetic parameter (endogenous metabolism, autotrophic biomass) & $d^{-1}$ \\
\hline $\mathrm{BOD}_{5}$ & Biochemical oxygen demand (5 days) & $\mathrm{kg} / \mathrm{m}^{3}$ \\
\hline CAS & Continuous-flow activated sludge process & \\
\hline COD & Chemical oxygen demand & $\mathrm{kg} / \mathrm{m}^{3}$ \\
\hline Eff & Effluent withdrawal phase (SBR) & \\
\hline HRT & Hydraulic residence time & d \\
\hline $\mathrm{HRT}_{1}$ & HRT for anoxic reactor (CAS, carbon and nitrogen removal) & \\
\hline $\mathrm{HRT}_{2}$ & HRT for aerobic reactor (CAS, carbon and nitrogen removal) & \\
\hline Ks & Kinetic parameter (readily biodegradable substrate) & $\mathrm{kg} \mathrm{COD} / \mathrm{m}^{3}$ \\
\hline $\mathrm{Kx}$ & Kinetic parameter (slowly biodegradable substrate) & kg COD/kg \\
\hline $\mathrm{kh}_{\mathrm{h}}$ & Kinetic parameter (slowly biodegradable substrate) & $\mathrm{kg} \mathrm{COD} / \mathrm{kg} / \mathrm{d}$ \\
\hline $\mathrm{K}_{\mathrm{SNO} 3}$ & Kinetic parameter (anoxic growth of heterotrophic biomass) & $\mathrm{kg} \mathrm{N}-\mathrm{NO}_{3} / \mathrm{m}^{3}$ \\
\hline $\mathrm{K}_{\mathrm{SNH} 3}$ & Kinetic parameter (growth of autotrophic biomass) & $\mathrm{kg} \mathrm{N}-\mathrm{NH}_{3} / \mathrm{m}^{3}$ \\
\hline $\mathrm{NH}_{3}$ & Ammonia concentration & $\mathrm{kg} \mathrm{N}-\mathrm{NH}_{3} / \mathrm{m}^{3}$ \\
\hline $\mathrm{NH}_{30}$ & $\mathrm{NH}_{3}$ in feed stream & $\mathrm{kg} \mathrm{N}-\mathrm{NH}_{3} / \mathrm{m}^{3}$ \\
\hline $\mathrm{NH}_{31}$ & $\mathrm{NH}_{3}$ in anoxic reactor (CAS, carbon and nitrogen removal) & $\mathrm{kg} \mathrm{N}-\mathrm{NH}_{3} / \mathrm{m}^{3}$ \\
\hline $\mathrm{NH}_{32}$ & $\mathrm{NH}_{3}$ in aerobic reactor (CAS, carbon and nitrogen removal) & $\mathrm{kg} \mathrm{N}-\mathrm{NH}_{3} / \mathrm{m}^{3}$ \\
\hline $\mathrm{NO}_{3}$ & Nitrate concentration & $\mathrm{kg} \mathrm{N}-\mathrm{NO}_{3} / \mathrm{m}^{3}$ \\
\hline $\mathrm{NO}_{31}$ & $\mathrm{NO}_{3}$ in anoxic reactor (CAS, carbon and nitrogen removal) & $\mathrm{kg} \mathrm{N}-\mathrm{NO}_{3} / \mathrm{m}^{3}$ \\
\hline $\mathrm{NO}_{32}$ & $\mathrm{NO}_{3}$ in aerobic reactor (CAS, carbon and nitrogen removal) & $\mathrm{kg} \mathrm{N}-\mathrm{NO}_{3} / \mathrm{m}^{3}$ \\
\hline $\mathrm{NO}_{3 \text { Aer }}$ & $\mathrm{NO}_{3}$ at the end of the aerobic phase (SBR, carbon and nitrogen removal) & $\mathrm{kg} \mathrm{N}-\mathrm{NO}_{3} / \mathrm{m}^{3}$ \\
\hline $\mathrm{NO}_{3 \text { Anox }}$ & $\mathrm{NO}_{3}$ at the end of the anoxic phase (SBR, carbon and nitrogen removal) & $\mathrm{kg} \mathrm{N}-\mathrm{NO}_{3} / \mathrm{m}^{3}$ \\
\hline No cycles & Number of cycles per day & $d^{-1}$ \\
\hline Px & Sludge production flow rate & $\mathrm{kg} / \mathrm{d}$ \\
\hline Q & Influent flow rate & $m^{3} / d$ \\
\hline Qiill & Influent flow rate during the filling phase (SBR) & $\mathrm{m}^{3} / \mathrm{d}$ \\
\hline$Q_{R}$ & Sludge recycle flow rate & $m^{3} / d$ \\
\hline Q! & Internal recycle flow rate & $\mathrm{m}^{3} / \mathrm{d}$ \\
\hline Qw & Sludge withdrawal flow rate & $m^{3} / d$ \\
\hline Qwith & Sludge withdrawal flow rate during the sludge withdrawal phase (SBR) & $\mathrm{m}^{3} / \mathrm{d}$ \\
\hline Qozbiomass & Oxygen consumption by the microorganisms (total) & $\mathrm{kg} / \mathrm{d}$ \\
\hline Qo2biomass,het & Oxygen consumption by the heterotrophic biomass & $\mathrm{kg} / \mathrm{d}$ \\
\hline Qo2biomass,aut & Oxygen consumption by the autotrophic biomass & $\mathrm{kg} / \mathrm{d}$ \\
\hline & Sludge recycle ratio & dimensionless \\
\hline $\mathrm{R}_{\mathrm{I}}$ & Internal recycle ratio & dimensionless \\
\hline rhydr & Hydrolysis rate of the slowly biodegradable substrate & $\mathrm{kg} \mathrm{COD} / \mathrm{m}^{3} / \mathrm{d}$ \\
\hline rXAer & Growth rate of heterotrophic biomass (aerobic) & $\mathrm{kg} / \mathrm{m}^{3} / \mathrm{d}$ \\
\hline rXAnox & Growth rate of heterotrophic biomass (anoxic) & $\mathrm{kg} / \mathrm{m}^{3} / \mathrm{d}$ \\
\hline rendAer & Endogenous metabolism rate of heterotrophic biomass (aerobic) & $\mathrm{kg} / \mathrm{m}^{3} / \mathrm{d}$ \\
\hline rendAnox & Endogenous metabolism rate of heterotrophic biomass (anoxic) & $\mathrm{kg} / \mathrm{m}^{3} / \mathrm{d}$ \\
\hline rendA & Endogenous metabolism rate of autotrophic biomass & $\mathrm{kg} / \mathrm{m}^{3} / \mathrm{d}$ \\
\hline rSAer & Organic substrate removal rate (aerobic) & $\mathrm{kg} \mathrm{COD} / \mathrm{m}^{3} / \mathrm{d}$ \\
\hline rSAnox & Organic substrate removal rate (anoxic) & $\mathrm{kg} \mathrm{COD} / \mathrm{m}^{3} / \mathrm{d}$ \\
\hline rNH3Aer & Ammonia removal rate (aerobic) & $\mathrm{kg} \mathrm{N}-\mathrm{NH}_{3} / \mathrm{m}^{3} / \mathrm{d}$ \\
\hline rNH3Anox & Ammonia removal rate (anoxic) & $\mathrm{kg} \mathrm{N}-\mathrm{NH}_{3} / \mathrm{m}^{3} / \mathrm{d}$ \\
\hline rNO3Aer & Nitrate removal rate (aerobic) & $\mathrm{kg} \mathrm{N}-\mathrm{NO}_{3} / \mathrm{m}^{3} / \mathrm{d}$ \\
\hline rNO3Anox & Nitrate removal rate (anoxic) & $\mathrm{kg} \mathrm{N}-\mathrm{NO}_{3} / \mathrm{m}^{3} / \mathrm{d}$ \\
\hline S & Readily biodegradable substrate concentration & $\mathrm{kg} \mathrm{COD} / \mathrm{m}^{3}$ \\
\hline So & $S$ in feed stream & $\mathrm{kg} \mathrm{COD} / \mathrm{m}^{3}$ \\
\hline $\mathrm{S}_{1}$ & $S$ in anoxic reactor (CAS, carbon and nitrogen removal) & $\mathrm{kg} \mathrm{COD} / \mathrm{m}^{3}$ \\
\hline
\end{tabular}


$\mathrm{S}_{2}$

SBR

SRT

tAerfill

tAerreact

tAnoxfill

tAnoxreact

tcycle

teff

$t_{\text {settle }}$

$t_{w}$

V

$V_{\text {full }}$

$\mathrm{V}_{1}$

$\mathrm{V}_{2}$

W

$X$

$X_{R}$

$X_{1}$

$X_{2}$

$X_{A}$

$X_{A 1}$

$\mathrm{X}_{\mathrm{A} 2}$

$X_{A R}$

$X_{S}$

$\mathrm{X}_{\mathrm{s} 0}$

$Y_{X / S}$

$Y_{X A / N O 3}$

$\mu_{\max }$

$\mu_{\max \mathrm{A}}$
$S$ in aerobic reactor (CAS, carbon and nitrogen removal)

Sequencing batch reactor

Solids residence time

Length of the aerobic filling phase

Length of the aerobic reaction phase

Length of the anoxic filling phase

Length of the anoxic reaction phase

Length of the entire cycle

Length of the effluent withdrawal phase

Length of the settling phase

Length of the sludge withdrawal phase

Reactor volume

Volume of the SBR when full

$\mathrm{V}$ of anoxic reactor (CAS, carbon and nitrogen removal)

$V$ of aerobic reactor (CAS, carbon and nitrogen removal)

Sludge withdrawal phase (SBR)

Heterotrophic biomass concentration

$X$ at the bottom of the settling tank (CAS)

$X$ in in anoxic reactor (CAS, carbon and nitrogen removal)

$X$ in in aerobic reactor (CAS, carbon and nitrogen removal)

Autotrophic biomass concentration

$\mathrm{X}_{\mathrm{A}}$ in in anoxic reactor (CAS, carbon and nitrogen removal)

$\mathrm{X}_{\mathrm{A}}$ in in aerobic reactor (CAS, carbon and nitrogen removal)

$\mathrm{X}_{\mathrm{A}}$ at the bottom of the settling tank (CAS)

Slowly biodegradable substrate concentration

$X_{s}$ in feed stream

Yield of heterotrophic biomass on COD

Yield of autotrophic biomass on nitrate

Kinetic parameter (aerobic and anoxic growth of heterotrophic biomass)

Kinetic parameter (growth of autotrophic biomass) $\mathrm{kg} \mathrm{COD} / \mathrm{m}^{3}$

d

d

d

d

d

d

d

d

d

$m^{3}$

$m^{3}$

$\mathrm{m}^{3}$

$\mathrm{m}^{3}$

$\mathrm{kg} / \mathrm{m}^{3}$

$\mathrm{kg} / \mathrm{m}^{3}$

$\mathrm{kg} / \mathrm{m}^{3}$

$\mathrm{kg} / \mathrm{m}^{3}$

$\mathrm{kg} / \mathrm{m}^{3}$

$\mathrm{kg} / \mathrm{m}^{3}$

$\mathrm{kg} / \mathrm{m}^{3}$

$\mathrm{kg} / \mathrm{m}^{3}$

$\mathrm{kg} \mathrm{COD} / \mathrm{m}^{3}$

$\mathrm{kg} \mathrm{COD} / \mathrm{m}^{3}$

$\mathrm{kg} / \mathrm{kg}$ COD

$\mathrm{kg} / \mathrm{kg} \mathrm{N}-\mathrm{NO}_{3}$

$d^{-1}$

$d^{-1}$ 


\section{Introduction}

Biological wastewater treatment is used globally to process large volumes of municipal and industrial wastewaters, with the aim of reducing the concentration of organic matter and in some cases of nitrogen before the treated wastewaters can be safely discharged into the environment. Aerobic processes are the most common for biological wastewater treatment processes and are very energy intensive, due to the energy requirements for aeration, which account for $47-70 \%$ of the total energy consumption of the process (Daverey et al., 2019). It is estimated that $3 \%$ of the electrical energy consumption in the US is due to biological wastewater treatment processes (McCarty et al., 2011). In the design of biological wastewater treatment processes, it is important to choose the process configuration and the operating parameters that maximise the removal of the organic matter and, if required, nitrogen and minimise energy consumption.

The continuous-flow activated sludge process (CAS) and the sequencing batch reactor (SBR) are common process configurations for biological wastewater treatment (Henze et al., 2008), based on suspended-growth open mixed cultures. The CAS is the most common process and consists, in its simplest configuration, of a biological reactor followed by a settling tank, which generates concentrated microorganisms for recycling to the reactor and for withdrawal and a clarified effluent stream. The SBR is one of the alternatives to the CAS and is characterised by a sequence of phases in the same vessel. In its simplest configuration, the SBR consists of a fill phase, followed by a reaction phase, sludge withdrawal, settling and effluent withdrawal. After the clarified effluent is withdrawn, a new cycle is started with a new fill.

Although the CAS process has been in use for approximately 100 years and the SBR for several decades and they have been the subject of many published papers, little 
theoretical or experimental study has been published on the comparison of the performance (e.g. COD and nitrogen removal, oxygen consumption) of these processes. Understanding the differences between the CAS and the SBR and the effect of operating parameters on their performance is important in order to choose the most suitable configuration and to achieve the desired treatment efficiency with the minimum energy consumption. Mirbagheri et al. (2017) compared the performance of CAS, SBR and other process configurations at pilot scale for a municipal wastewater and found that SBR gave a higher $\mathrm{BOD}_{5}$ removal than the CAS. Wanner (1992) found similar performance for SBR and CAS processes for COD and nitrogen removal for a municipal wastewater. Papadimitrou et al. (2009) compared SBR and CAS processes for the treatment of an industrial wastewater, obtaining higher removal of $\mathrm{COD}$ and $\mathrm{BOD}_{5}$ in the SBR.

The limitation of the cited and of other experimental studies on the comparison of SBR and CAS is that those findings are only valid for the particular wastewater and process conditions which were investigated. To fill this gap, this study is aimed at a theoretical comparison of the CAS and the SBR, identifying the expected analogies and differences in the performance of these processes for different operating parameters and process scenarios. The comparison is based on kinetic models of biological wastewater treatment and on the solution of steady-state mass balances, using, for the SBR, the method we developed for the calculation of the periodic steady state (Dionisi et al., 2016). SBR and CAS are compared for the processes for carbon removal and for carbon and nitrogen removal. The CAS and SBR are compared for their removal of carbon and nitrogen, for oxygen consumption and sludge production, providing insight into how to choose the best process configuration and how to optimise process performance. 


\section{Methodology}

\subsection{Process configurations}

The process configurations considered in this study for the CAS and SBR are shown in Figures 1 and 2, respectively. In all cases, the biological reactors are assumed to be completely mixed and the settling process is assumed to be perfect, with no microorganisms leaving with the clarified effluent. We assume that no reactions occur during settling. All species, except the microorganisms, are assumed to be soluble and their concentration is assumed not to change in the settling process.

The CAS for carbon removal (Figure 1a) is modelled as a continuous-flow process with a completely-mixed reactor followed by a settling tank. In the biological reactor, heterotrophic microorganisms remove the organic substrate. The settling tank separates the microorganisms, which are partly recycled and partly withdrawn. The CAS for carbon and nitrogen removal (Figure 1b) is modelled as a sequence of two reactors, anoxic and aerobic, followed by settling tank. In the anoxic reactor the heterotrophic microorganisms remove the organic substrate using nitrate as electron acceptor. In the aerobic reactor, the heterotrophic microorganisms remove the residual organic matter and the autotrophic microorganisms convert ammonia into nitrate. Nitrate is recycled back into the anoxic reactor via the internal recycle. The processes occurring in the SBR are the same as in the CAS. The SBR is modelled as a sequence of phases. The cycle of the SBR for carbon removal (Figure 2a) starts with the fill phase, followed by the reaction phase and by the sludge withdrawal phase (fill, reaction and sludge withdrawal are aerated and mixed). After sludge withdrawal, the settling phase separates the microorganisms from the soluble species. At the end of the settling phase, the effluent is withdrawn and a new 
cycle starts with a new fill. The SBR for carbon and nitrogen removal has a similar cycle pattern as the SBR for carbon removal, but the reaction phase is split into anoxic and aerobic phases. Similarly to the corresponding CAS process, the fill for the SBR for carbon and nitrogen removal occurs under anoxic conditions.

The carbon removal processes (SBR and CAS) were simulated in two scenarios with a feed composed of only readily biodegradable and of only slowly biodegradable substrates. The carbon and nitrogen removal processes were only simulated with a feed composed of readily biodegradable substrates.

The values of the operating parameters used in the base case for the SBR and CAS are shown in Table 1.

\subsection{Kinetic models}

The reaction kinetics considered in this study are the same for the CAS and the SBR and are reported below. Equations (1)-(13) represent a model with microorganisms growth and endogenous metabolism and are typical reaction rates used for biological wastewater treatment processes. We assume that endogenous metabolism converts microorganisms into carbon dioxide and water, with no generation of inerts. The values of the parameters used in this study are reported in Table 2 and are typical values for these processes. Equations (1)-(13), their derivations and the values used for the parameters can be found in the literature (Henze et al., 2000; Dionisi, 2017). We assumed that the limiting substrates are: COD for the aerobic metabolism of heterotrophic microorganisms; COD and nitrate for the anoxic metabolism of heterotrophic microorganisms; ammonia for the aerobic metabolism of autotrophic microorganisms. We assumed that oxygen is in excess in aerobic conditions and is not present in anoxic conditions. 


$$
\begin{aligned}
& r_{\text {XAer }}=\mu_{\max } \frac{S}{K_{\mathrm{S}}+S} X \\
& r_{\text {endAer }}=-b X \\
& r_{\mathrm{XAnox}}=\mu_{\max } \frac{S}{K_{\mathrm{S}}+S} \frac{\mathrm{NO}_{3}}{\mathrm{~K}_{\mathrm{SNO}_{3}}+\mathrm{NO}_{3}} X \\
& r_{\text {endAnox }}=-b \frac{\mathrm{NO}_{3}}{\mathrm{~K}_{\mathrm{SNO}_{3}}+\mathrm{NO}_{3}} X \\
& r_{\mathrm{XA}}=\mu_{\operatorname{maxA}} \frac{\mathrm{NH}_{3}}{\mathrm{~K}_{\mathrm{SNH}_{3}}+\mathrm{NH}_{3}} X_{\mathrm{A}} \\
& r_{\text {endA }}=-b_{\mathrm{A}} X_{\mathrm{A}} \\
& r_{\text {hydr }}=-k_{\mathrm{h}} \frac{X_{\mathrm{S}} / X}{K_{\mathrm{X}}+X_{\mathrm{S}} / X} X \\
& r_{S A e r}=-\frac{r_{\text {XAer }}}{Y_{X / S}} \\
& r_{\text {SAnox }}=-\frac{r_{\mathrm{XAnox}}}{Y_{X / S}} \\
& r_{\text {NH3Anox }}=-\left(r_{X \text { Anox }}+r_{\text {endAnox }}\right) \cdot 0.12 \\
& r_{N H 3 A e r}=-r_{X A}\left(0.12+\frac{1}{Y_{X A / N O 3}}\right)-r_{e n d A} \cdot 0.12-\left(r_{X A e r}+r_{e n d A e r}\right) \cdot 0.12 \\
& r_{\text {NO3Anox }}=\frac{-r_{X A \operatorname{nox}}\left(\frac{1}{Y_{X / S}}-1.42\right)+1.42 \cdot r_{\text {endAnox }}}{2.86} \\
& r_{N O 3 A e r}=\frac{r_{X A}}{Y_{X A / N O 3}}
\end{aligned}
$$

\subsection{Mass balances}

The steady state values of the CAS were calculated by solving the steady state mass balances that describe the process. For the SBR, a periodic steady state was defined as the condition when the time profiles of all the variables during a cycle don't change between consecutive cycles. The periodic steady state for the SBR was calculated by solving the mass balances and imposing the condition that the initial and final value of each variable during the cycle are the same. 
In this section, we summarise the mass balances which were solved for the various process configurations. Derivation and explanation of the equations and their solution methods (Microsoft Excel, Solver add-in) are shown in our previous work (Dionisi, 2017; Dionisi et al., 2016).

2.3.1 CAS, carbon removal with readily biodegradable substrate in the feed In this configuration, the key operating parameters are the SRT and the HRT, which are expressed as:

$S R T=\frac{V X}{Q_{W} X_{R}}$

$H R T=\frac{V}{Q}$

The steady state mass balances are reported by Equations (16)-(18).

Heterotrophic microorganisms in the reactor:

$\frac{\left(r_{X A e r}+r_{e n d A e r}\right)}{X}+\frac{R X_{R}}{X \cdot H R T}=\frac{(1+R)}{H R T}$

Organic substrate in the reactor:

$\frac{\left(S_{0}-S\right)}{X \cdot H R T}=\frac{-r_{S A e r}}{X}$

Heterotrophic microorganisms in the whole system (reactor+settling tank):

$\frac{\left(r_{X A e r}+r_{e n d A e r}\right)}{X}=\frac{1}{S R T}$

The steady state values for $S, X$ and $X_{R}$ were calculated by solving Equations (16)-(18) for given values of SRT, HRT and R. After the solutions of Equations (16)-(18), the oxygen consumption by the microorganisms and the sludge production were calculated from Equations (19) and (20):

$\frac{Q_{\text {O2biomass }}}{Q}=\left(S_{0}-S\right)-\frac{X \cdot H R T}{S R T} \cdot 1.42$ 
$\frac{P_{X}}{Q}=\frac{H R T \cdot X}{S R T}$

2.3.2 CAS, carbon removal with slowly biodegradable substrate in the feed

The definition of SRT and HRT are still given by Equations (14) and (15). The steady state mass balances for heterotrophic microorganisms in the reactor and in the whole system are still given by Equations (16) and (18). The mass balances for the slowly and readily biodegradable substrate in the reactor are given by Equations (21) and (22), respectively.

$\frac{\left(X_{S 0}-X_{S}\right)}{X \cdot H R T}=\frac{r_{\text {hydr }}}{X}$

$\frac{\left(S_{0}-S\right)}{X \cdot H R T}+\frac{r_{\mathrm{hydr}}}{X}=\frac{-r_{S A e r}}{X}$

The steady state for this process was calculated by solving Equations (16), (18), (21), (22) for the variables, $X_{S}, S, X$ and $X_{R}$ for given values of SRT, HRT and R. The oxygen consumption and sludge production were still calculated from Equations (19) and (20). 2.3.3 CAS, carbon and nitrogen removal

In this configuration the SRT is defined as:

$S R T=\frac{V_{1}\left(X_{1}+X_{A 1}\right)+V_{2}\left(X_{2}+X_{A 2}\right)}{Q_{w}\left(X_{R}+X_{A R}\right)}$

There are two values for the HRT, $\mathrm{HRT}_{1}$ and $\mathrm{HRT}_{2}$, referred to reactor 1 and 2, respectively:

$H R T_{1}=\frac{V_{1}}{Q}$

$H R T_{2}=\frac{V_{2}}{Q}$

The process is characterised by the mass balances (26)-(37).

Heterotrophic biomass in reactor 1: 
$\frac{\left(r_{X A n o x}+r_{\text {endAnox }}\right)}{X_{1}}+\frac{R X_{R}}{X_{1} H R T_{1}}+\frac{R_{I} X_{2}}{X_{1} H R T_{1}}=\frac{\left(1+R+R_{I}\right)}{H R T_{1}}$

Autotrophic biomass in reactor 1 :

$\frac{R X_{A R}}{X_{A 1} H R T_{1}}+\frac{R_{I} X_{A 2}}{X_{A 1} H R T_{1}}=\frac{\left(1+R+R_{I}\right)}{H R T_{1}}$

Heterotrophic biomass in reactor 2:

$\frac{\left(r_{X 2}+r_{e n d 2}\right)}{X_{2}}+\frac{\left(1+R+R_{I}\right) X_{1}}{X_{2} H R T_{2}}=\frac{\left(1+R+R_{I}\right)}{H R T_{2}}$

Autotrophic biomass in reactor 2:

$\frac{\left(r_{X A 2}+r_{e n d A 2}\right)}{X_{A 2}}+\frac{\left(1+R+R_{I}\right) X_{A 1}}{X_{A 2} H R T_{2}}=\frac{\left(1+R+R_{I}\right)}{H R T_{2}}$

Heterotrophic biomass in the whole system:

$\frac{\left(r_{X 1}+r_{\text {end } 1}\right)}{X_{1}}+\left(r_{X 2}+r_{e n d 2}\right) \frac{H R T_{2}}{X_{1} H R T_{1}}=\frac{X_{R}}{X_{1} H R T_{1}}\left(\frac{H R T_{1}\left(X_{1}+X_{A 1}\right)+H R T_{2}\left(X_{A 2}+X_{2}\right)}{S R T\left(X_{R}+X_{A R}\right)}\right)$

Autotrophic biomass in the whole system:

$\frac{\left(r_{X A 2}+r_{e n d A 2}\right)}{X_{A 2}}=\frac{X_{A R}}{X_{A 2} H R T_{2}}\left(\frac{H R T_{1}\left(X_{1}+X_{A 1}\right)+H R T_{2}\left(X_{A 2}+X_{2}\right)}{S R T\left(X_{R}+X_{A R}\right)}\right)$

Carbon substrate in reactor 1 :

$\frac{S_{0}+R S_{2}+R_{I} S_{2}}{X_{1} H R T_{1}}=\frac{\left(-r_{\text {SAnox }}\right)}{X_{1}}+\frac{\left(1+R+R_{I}\right) S_{1}}{X_{1} H R T_{1}}$

Carbon substrate in reactor 2:

$\frac{\left(1+R+R_{I}\right) S_{1}}{X_{2} H R T_{2}}=\frac{\left(-r_{S A e r}\right)}{X_{2}}+\frac{\left(1+R+R_{I}\right) S_{2}}{X_{2} H R T_{2}}$

Ammonia in reactor 1 :

$\frac{r_{N H 3 A n o x}}{X_{1}}+\frac{N H_{30}+R N H_{32}+R_{I} N H_{32}}{X_{1} H R T_{1}}=\frac{\left(1+R+R_{I}\right) N H_{31}}{X_{1} H R T_{1}}$

Ammonia in reactor 2:

$\frac{r_{N H 3 A e r}}{X_{A 2}}+\frac{\left(1+R+R_{I}\right) N H_{31}}{X_{A 2} H R T_{2}}=\frac{\left(1+R+R_{I}\right) N H_{32}}{X_{A 2} H R T_{2}}$

Nitrate in reactor 1 : 
$\frac{R N O_{32}+R_{I} N O_{32}}{X_{1} H R T_{1}}=\frac{r_{N O 3 A n o x}}{X_{1}}+\frac{\left(1+R+R_{I}\right) N O_{31}}{X_{1} H R T_{1}}$

Nitrate in reactor 2:

$\frac{r_{N O 3 A e r}}{X_{A 2}}+\frac{\left(1+R+R_{I}\right) N O_{31}}{X_{A 2} H R T_{2}}=\frac{\left(1+R+R_{I}\right) N O_{32}}{X_{A 2} H R T_{2}}$

The steady state of the process was calculated by solving Equations (26)-(37) for the variables $\mathrm{S}_{1}, \mathrm{~S}_{2}, \mathrm{X}_{1}, \mathrm{X}_{2}, \mathrm{X}_{\mathrm{A} 1}, \mathrm{X}_{\mathrm{A} 2}, \mathrm{NH}_{31}, \mathrm{NH}_{32}, \mathrm{NO}_{31}, \mathrm{NO}_{32}, \mathrm{X}_{\mathrm{R}}, \mathrm{X}_{\mathrm{AR}}$ for given values of SRT, HRT $1, H R T_{2}, R$ and RI. Once Equations (26)-(37) were solved, the sludge production and oxygen consumption were calculated from equations (38)-(41).

$P_{X}=\frac{H R T \cdot\left(X_{R}+X_{A R}\right)}{S R T}$

$Q_{\text {O2biomass }}=Q_{\text {o2biomass, het }}+Q_{\text {o2biomass,aut }}$

$\frac{Q_{\text {ozbiomass,het }}}{Q}=\left(S_{0}-S\right)-\frac{H R T \cdot X_{R}}{S R T} \cdot 1.42-\left[\left(R_{I}+R\right) N O_{32}-\left(1+R+R_{I}\right) N O_{31}\right] \cdot 2.86$

$\frac{Q_{\text {O2biomass,aut }}}{Q}=\left(4.57-1.42 Y_{X A / N O 3}\right)\left(N O_{32}-N O_{31}\right)\left(1+R+R_{I}\right)+\frac{b_{A} X_{A 2} 1.42}{H R T_{2}}$

The total nitrogen removal was calculated from Equation (42):

Total nitrogen removal $=\left(\frac{\mathrm{NH}_{30}-\left(\mathrm{NO}_{32}+\mathrm{NH}_{32}\right)}{\mathrm{NH}_{30}}\right) \cdot 100$

2.3.4 SBR, carbon removal with readily biodegradable substrates in the feed The key design parameters are the HRT and SRT which are expressed as follows:

$S R T=\frac{V_{\text {full }}}{Q_{\text {With }} t_{\text {WNocycles }}}$

$H R T=\frac{V_{\text {full }}}{Q_{\text {fill }} f_{\text {fill }} \text { Nocycles }}$

The mass balances of biomass, substrate and reactor volume are shown in Equations (45)-(47). In the mass balances for the SBR, we used the notation $\left.f(x)\right|_{\text {Nameof the phas }(s)}$ to mean that the function $f(x)$ is non zero only during the specified phase(s) and equal to 0 during the rest of the cycle (Dionisi et al., 2016). 
Biomass (at the periodic steady state):

$\int_{\text {cycle }}\left[\left.\left(r_{X A e r}+r_{\text {endAer }}\right)\right|_{\text {AerFill,AerReact, } W}-\frac{X}{V / V_{\text {full }}} \frac{1}{\text { HRT.t }}\right.$ Aerfill Nocycles $\left.\right|_{\text {AerFill }}+$

$\left.\left.\frac{X}{{ }^{V} / V_{\text {full }}} \frac{1}{\text { Nocycles } t_{\text {eff }}}\left(\frac{1}{H R T}-\frac{1}{S R T}\right)\right|_{W}\right] d t=0$

Substrate (at the periodic steady state):

$\int_{\text {cycle }}\left[\left.r_{\text {SAer }}\right|_{\text {AerFill,AerReact }, W}+\left.\frac{1}{H R T \cdot t_{\text {Aerfill }} \text { Nocycles }} \frac{\left(S_{0}-S\right)}{V / V_{\text {full }}}\right|_{\text {AerFill }}\right] d t=0$

Reactor volume:

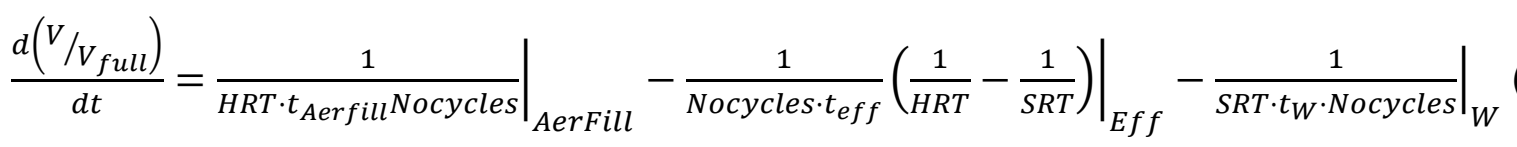

The periodic steady state was calculated from the solutions of Equations (45)-(47). For given values of the length of the phases, Nocycles, HRT and SRT, the solution of Equations (45)-(47) gave the profiles of $S(t), X(t)$ and $V / V_{\text {full }}(t)$ at the periodic steady state. After the solution of Equations (45)-(47), the sludge production and oxygen consumption were calculated from Equations (19) and (20), using the calculated value of $X$ at the end of the sludge withdrawal phase.

2.3.5 SBR, carbon removal with slowly biodegradable substrates in the feed

The SRT and HRT are still defined by Equations (43) and (44) and the mass balance for biomass by Equation (45). The balance for the reactor volume is given by Equation (47). The balances for the slowly and readily biodegradable substrates are given by Equations (48) and (49).

Slowly biodegradable substrate (at the periodic steady state): 
$\int_{\text {cycle }}\left[\left.r_{\text {hydr }}\right|_{\text {AerFill,AerReact }, W}+\left.\frac{1}{H_{R T \cdot t_{\text {Aerfill }} \text { Nocycles }}} \frac{\left(X_{S 0}-X_{S}\right)}{V_{V_{\text {full }}}}\right|_{\text {AerFill }}\right] d t=0$

Readily biodegradable substrate (at the periodic steady state):

$\int_{\text {cycle }}\left[\left.\left(r_{S}-r_{\text {hydr }}\right)\right|_{\text {AerFill,AerReact,W }}-\left.\frac{1}{H R T \cdot t_{\text {Aerfill }} \text { Nocycles }^{V} / V_{\text {full }}}\right|_{\text {AerFill }}\right] d t=0$

The solution of Equations (45), (47)-(49) gave the profiles of $S(t), X(t)$ and $V / V_{\text {full }}(t)$ at the periodic steady state. The sludge production and oxygen consumption were calculated from Equations (19) and (20).

\subsubsection{SBR, carbon and nitrogen removal}

The SRT and HRT are still expressed by Equations (43) and (44). The mass balances are expressed by Equations (50)-(54).

Substrate (at the periodic steady state):

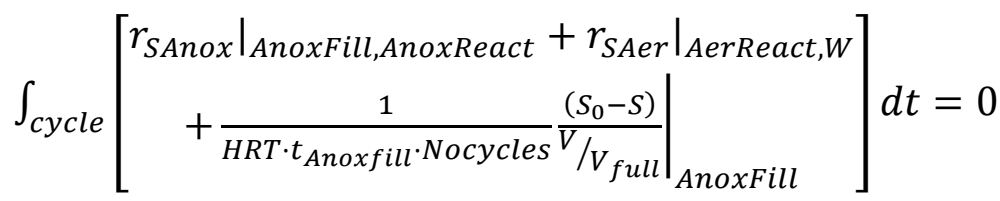

Heterotrophic biomass (at the periodic steady state):

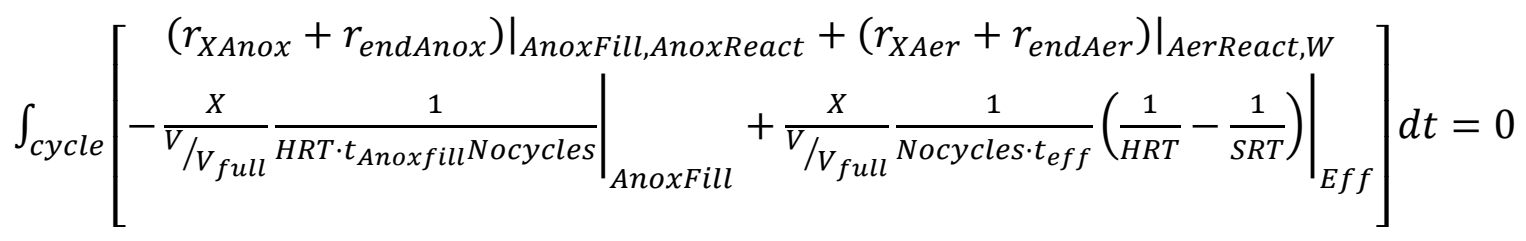

Autotrophic biomass (at the periodic steady state):

$\int_{\text {cycle }}\left[\begin{array}{l}\left.\left(r_{X A}+r_{\text {endA }}\right)\right|_{\text {AerReact }, W}-\left.\frac{X_{A}}{V / V_{\text {full }}} \frac{1}{H R T \cdot t_{\text {Anoxfill }} \text { Nocycles }}\right|_{\text {AnoxFill }} \\ \left.\frac{X_{A}}{V / V_{\text {full }}} \frac{1}{\text { Nocycles } t_{\text {eff }}}\left(\frac{1}{H R T}-\frac{1}{S R T}\right)\right|_{E f f}\end{array}\right] d t=0$

Ammonia (at the periodic steady state): 
$\int_{\text {cycle }}\left[\begin{array}{l}\left.r_{N H 3 \text { Anox }}\right|_{\text {AnoxFill,AnoxReact }}+\left.r_{N H 3 \text { Aer }}\right|_{\text {AerReact }, W} \\ +\left.\frac{1}{H R T \cdot t_{\text {Anoxfill }} \text { Nocycles }} \frac{\left(N H_{30}-N H_{3}\right)}{V^{\prime} V_{\text {full }}}\right|_{\text {AnoxFill }}\end{array}\right] d t=0$

Nitrate (at the periodic steady state):

$\int_{\text {cycle }}\left[\begin{array}{l}\left.r_{\text {NO3Anox }}\right|_{\text {AnoxFill,AnoxReact }} \\ +\left.r_{\text {NO3Aer }}\right|_{\text {AerReact }}+\left.\frac{1}{H R T \cdot t_{\text {Anoxfill }} \text { Nocycles }} \frac{-N O_{3}}{V / V_{\text {full }}}\right|_{\text {AnoxFill }}\end{array}\right] d t=0$

The periodic steady state was calculated by solving Equations (50)-(54) and (47), obtaining the profiles of $\mathrm{S}(\mathrm{t}), \mathrm{X}(\mathrm{t}), \mathrm{X}(\mathrm{t}), \mathrm{NH}_{3}(\mathrm{t}), \mathrm{NO}_{3}(\mathrm{t})$ and $\mathrm{V} / \mathrm{V}_{\text {full }}(\mathrm{t})$. The production of microorganisms was calculated from Equation (55) and the oxygen consumption from Equations (39), (56) and (57).

$\frac{P_{X}}{Q}=\frac{H R T \cdot\left(X+X_{A}\right)}{S R T}$

$\frac{Q_{\text {O2biomass,het }}}{Q}=\left(S_{0}-S\right)-\left(\frac{H R T}{S R T}\right) \times 1.42-\left(\left(H R T-\frac{1}{\text { No cycles }}\right) N O_{3 \text { Aer }}-H R T \cdot\right.$

$\left.N O_{3 \text { Anox }}\right)$ No cycles 2.86

$\frac{Q_{\text {O2biomass,aut }}}{Q}=H R T\left(N O_{3 A e r}-N O_{3 A n o x}\right)$ No cycles $\left(4.57-1.42 Y_{\frac{\mathrm{XA}}{\mathrm{NO}_{3}}}\right)+\left(\mathrm{b}_{\mathrm{A}} \mathrm{X}_{\mathrm{A}} \mathrm{HRT} 1.42\right)$

The total nitrogen removal was calculated with Equation (42) using the concentrations in the feed and in the effluent. 


\section{Results and discussion}

\subsection{Carbon removal}

Figure 3 shows the profiles of the effluent substrate in the CAS and SBR as a function of the SRT for the case with the influent substrate being readily biodegradable. The main difference between the CAS and the SBR is that in the former there is a residual substrate concentration in the effluent (although, with the parameters used in this study, this is very low, less than $1 \mathrm{mg} \mathrm{COD} / \mathrm{l})$, while in the latter the influent substrate is entirely removed. The reason for the difference in the residual substrate concentrations in the CAS and in the SBR is that the former is a completely-mixed continuous-flow process, while the latter, although is completely mixed, has intermittent feed. In the CAS, the mass balance for the biomass in the whole system, Equation (18), can be re-arranged as:

$S=\frac{b K_{S} S R T+K_{S}}{\left(\mu_{\max }-b\right) S R T-1}$

Equation (58) shows that for $S R T \rightarrow \infty, S \rightarrow S_{\min }=\frac{b K_{S}}{\left(\mu_{\max }-b\right)}$, so $S$ will be $>0$ as long as $\mathrm{b}$ and Ks are $>0$. The physical reason for this behaviour is that if the substrate concentration in the CAS was lower than $S_{\min }$, the net biomass growth rate $\left(\frac{\mu_{\max } S}{K_{S}+S}-b\right)$ would become negative, and, since biomass is continuously removed from the process, it wouldn't be possible to maintain any biomass concentration in the system. Therefore, any substrate concentration lower than $S_{\min }$ are impossible to be achieved in a CAS. The configuration of the SBR is different from the CAS in that biomass is not removed continuously but only intermittently at the end of the cycle. In the SBR substrate removal continues even when the substrate concentration reaches the $S_{\min }$ for the CAS, because substrate removal can 
proceed even when the net growth rate of the biomass is negative, as long as the biomass is not continuously removed from the system.

As the SRT decreases, the effluent substrate concentration in the CAS gradually increases until the minimum SRT is reached when no substrate removal occurs and the biomass concentration in the reactor becomes zero. In the SBR, the effluent substrate concentration remains equal to zero until it rises suddenly when the minimum SRT is reached, which corresponds to no substrate removal and no biomass concentration. Interestingly, the minimum SRT which corresponds to process failure is slightly higher for the SBR than for the CAS. For SRT>SRT min, the biomass concentration in the CAS and in the SBR is essentially the same, as the vast majority of the influent substrate is removed in both processes. Similarly, the oxygen consumption and the biomass production are essentially the same for the CAS and SBR (Figure 3b). Oxygen consumption increases as the SRT increases because of the increased role of endogenous metabolism and, for the same reason, biomass production decreases.

The biomass concentration in CAS and SBR processes is expected to depend on the HRT, as well on the SRT (Dionisi, 2017). Figure 4 shows that the biomass concentration is the same for both processes in a wide range of HRT values.

The difference between the effluent substrate concentration in the CAS and in the SBR is larger when the influent substrate is slowly biodegradable (Figure 5). In this case the SBR achieves complete removal of $\mathrm{Xs}$ and $\mathrm{S}$, while for the CAS the effluent concentration of Xs never goes below approximately $20 \mathrm{mg} / \mathrm{l}$.

Very limited comparison has been reported in the literature on COD removal for the same wastewater in SBR and CAS processes. Dockhorn et al. (2001) compared COD removal 
in SBR and continuous flow processes at 8 and $20 d$ SRT. At SRT $8 d$ the performance of SBR and CAS processes was virtually the same, while at SRT $20 d$ the COD removal by the SBR was slightly higher. Mirbagheri et al. (2017) compared the SBR, the CAS and other process configurations for the treatment of a municipal wastewater. Both the BOD and COD removal were higher in the SBR than in the CAS. The BOD removal in the SBR was $98-99 \%$ in all the investigated conditions, while for the CAS was in the range 85-93 \%. The COD removal was $94-95 \%$ in the SBR while it was $89-94 \%$ in the CAS. Even though the SRT in this study was not reported, and it was not specified whether it was the same in the CAS and SBR, these results are in qualitative agreement with our simulations. Indeed, the almost complete BOD removal observed in this experimental study agrees well with the complete removal of the biodegradable COD which we simulated for the SBR. It should be noted that, although in our study the simulated variable was the COD and not the BOD, we assumed that all the COD was biodegradable, and therefore it is reasonable to compare, at least qualitatively, our effluent COD with the effluent BOD of experimental studies with real wastewaters. With real wastewaters a fraction of the COD may not be biodegradable, and this may explain the incomplete removal of the COD in experimental studies. Mohan et al. (2005) compared SBR and CAS for the treatment of complex chemical effluents observing higher BOD (92 vs $67 \%$ ) and COD (66 vs $54 \%$ ) removal for the SBR. Although the conditions in the SBR and CAS were not identical (SRT was $10 \mathrm{~d}$ in the SBR and $12 \mathrm{~d}$ in the CAS, the HRT and the organic load rate were also different), these results are in qualitative agreement with our findings. Papadimitrou et al. (2009) compared a SBR and a CAS process for the treatment of a coke oven wastewater, obtaining higher removal of $\mathrm{COD}$ and $\mathrm{BOD}_{5}$ in the $\mathrm{SBR}$. In particular, the 
effluent $\mathrm{BOD}_{5}$ of the SBR was very close to zero, and significantly lower than in the CAS, in agreement with our simulations. Higher rate of COD removal in a lab-scale SBR than in the continuous-flow full scale plant was also observed for a tannery wastewater (Carucci et al., 1999). A survey of 14 SBR plants in Germany (Teichgräber, 2001) showed almost complete $\mathrm{BOD}_{5}$ removal, in agreement with this and other studies.

\subsection{Carbon and nitrogen removal}

Figure 6 compares the CAS and SBR in the process for carbon and nitrogen removal. The concentrations of heterotrophic and autotrophic biomass are essentially the same in both processes (Figure 6a). Analogously to what was observed for the process for carbon removal, the CAS has a residual substrate concentration in the effluent even at high SRT, while substrate degradation is complete for the SBR (Figure 6b). The concentration of effluent ammonia has the same trend as the one of the carbon substrate (Figure 6c): ammonia is completely removed in the SBR while there is a residual, although low, ammonia concentration in the effluent of the CAS. This is due to the fact that ammonia is the substrate for the autotrophic microorganisms and so the same considerations on the need of a minimum substrate concentration already made for carbon removal (Section 3.1) also apply to the autotrophic microorganisms. In the process of carbon and nitrogen removal, an important difference between the CAS and the SBR is the effluent nitrate concentration (Figure 6d), which is, at least with the base case process parameters, higher for the SBR. The higher nitrate concentration in the SBR corresponds to a lower extent of nitrogen removal in this process (Figure 6e). The reason for the higher effluent nitrate concentration in the SBR than in the CAS lies in the different operational mode of these processes. In both processes, the effluent nitrate concentration is determined by 
the ammonia concentration at the inlet of the aerobic reactor (for the CAS) or at the start of the aerobic phase (for the SBR). The ammonia concentration at the inlet of the aerobic reactor in the CAS is mainly determined by the sludge and internal recycle ratios, which dilute the ammonia concentration in the feed. In the SBR instead, there are no recycle streams and ammonia concentration at the start of the aerobic phase is mainly determined by the number of cycles per day and by the HRT, which have the effect of diluting the ammonia concentration in the feed. With the process parameters of the base cases in Figure $6(R \mid=R=1$ for the $C A S$, Nocycles $=4, H R T=0.3 d$ for the $S B R)$, the dilution of ammonia in the feed is larger for the CAS than for the SBR, resulting in lower effluent nitrate and higher nitrogen removal for the CAS. Figures $6 \mathrm{~d}$ and $6 \mathrm{e}$ also show a slight increase in the effluent nitrate and, correspondingly, a slight decrease in the nitrogen removal, for both processes as the SRT increases. This is due to the increased contribution of endogenous metabolism as the SRT increases. Endogenous metabolism causes a release of ammonia, which is then nitrified increasing the effluent nitrate concentration.

Figure 7 shows the effect of HRT on nitrogen removal. For the CAS, the HRT has no effect on nitrogen removal, because in this continuous-flow process the ammonia dilution, which is a key factor determining the effluent nitrate concentration, is determined by the ratio of the influent, sludge recycle and internal recycle flow rates (i.e. by the recycle ratios) and not by the volume of the reactors. For the SBR, on the other hand, the ratio between the influent flow rate and the reactor volume (i.e. the HRT) affects the dilution of the ammonia in the feed and, correspondingly, the effluent nitrate concentration and the nitrogen removal. Increasing the HRT corresponds to increasing the reactor volume per 
unit of influent flow rate, therefore increasing the dilution of the influent ammonia. Higher dilutions of the influent ammonia give lower ammonia concentrations at the start of the aerobic phase and, correspondingly, lower nitrate concentrations in the effluent and higher nitrogen removal.

Figure 8 shows the effect of the number of cycles in the SBR and of the internal recycle in the CAS. These two parameters, although they are different, have the similar function, as far as nitrogen removal is concerned, of diluting the ammonia concentration in the feed. For the CAS, increasing the internal recycle decreases the effluent nitrate and therefore increases the nitrogen removal. For the SBR, increasing the number of cycles per day, at a constant HRT, decreases the ammonia concentration at the end of the feeding period, and therefore also at the start of the aerobic phase, because the same volume of feed is split between a larger number of cycles. The lower ammonia concentration in turn corresponds to a lower nitrate concentration and a higher nitrogen removal.

Figure 9 compares the oxygen consumption in the CAS and SBR, as a function of the SRT and of the internal recycle (for the CAS) or number of cycles per day (for the SBR). In all cases the oxygen consumption increases as the SRT increases because of the increased effect of endogenous metabolism (same effect already observed for carbon removal). Oxygen consumption is lower for higher values of the internal recycle for the CAS and for higher values of the number of cycles for the SBR. The reason for this effect is that oxygen consumption decreases as nitrogen removal increases, because part of the COD is oxidised by nitrate rather than by oxygen. In all cases the biomass production 
as a function of the SRT for the conditions reported in Figure 9 is virtually the same, confirming what was observed for the process for carbon removal in Figure $3 b$.

Although many studies have been published on either SBR or CAS processes for nitrogen removal, comparison of the nitrogen removal of these processes for the same wastewater are very limited. Sun et al. (2019) compared ammonia and total nitrogen removal in anaerobic/anoxic/aerobic SBR and CAS processes. The SBR was operated with 4 cycles per day and the CAS with an internal recycle ratio of 1 . They observed almost complete ammonia removal in both processes but, in qualitative agreement with the present study, observed higher total nitrogen removal in the CAS than in the SBR. Almost complete ammonia removal in SBR processes was reported in a number of experimental studies (e.g. Yalmaz et al., 2001; Andreottola et al., 2001), in agreement with the results of our simulations. The effect of the HRT (at a fixed number of cycles per day as in our simulations in Figure 7) on nitrogen removal in SBR was experimentally investigated by Klimiuk et al. (2005), who observed an increase in nitrogen removal as the HRT increased, in agreement with our study. As far as the effect of the number of SBR cycles per day is concerned, Artan et al. (2002) simulated, based on a mathematical model of the SBR, SBR performance for 4-6 cycles per day, observing, in agreement with our study, a decrease in total nitrogen removal as the number of cycles per day decreased.

\subsection{General discussion and comparison of SBR and CAS processes}

This study highlighted, based on mathematical modelling, similarities and differences between SBR and CAS processes. The results of this study are important for the initial stage of process design, when the type of biological process (SBR or CAS) is chosen and 
when the key process operating parameters, i.e. SRT, HRT, recycle ratios, number of cycles per day, are chosen.

As far as the similarities are concerned, for carbon removal processes the biomass concentration and oxygen consumption are expected to be virtually the same, for the same SRT. In both process configurations, by increasing the SRT the oxygen consumption increases and the biomass production decreases. Higher oxygen consumption corresponds to higher energy consumption and operating costs. If the produced biomass is used, as it is done frequently, in an anaerobic digestion process for methane production and energy recovery, lower biomass production translates into lower energy recovery. Therefore, in order to minimise the overall energy input into the process, both the CAS and the SBR processes should be operated with the shortest possible SRT that ensures the desired removal of the organic matter. Successful investigation of activated sludge process operated at short SRT has recently been reported (e.g. Ge et al., 2017).

One important advantage of SBR vs CAS processes is predicted to be the lower concentration of substrate (organic matter and/or ammonia) in the effluent. This effect is expected to be more important for slowly biodegradable substrates, i.e. for substrates which need to be hydrolysed before being metabolised by microorganisms. Since generally most of the COD in domestic sewage is slowly biodegradable (Ohron et al., 1999), our study indicates that the SBR can potentially have a significant impact in improving the quality of the effluent wastewaters. However, systematic experimental comparison of the removal of slowly biodegradable substrates in SBR and CAS processes is limited. Therefore, one recommendation from this study is to carry out a 
systematic experimental investigation of COD removal in SBR and CAS processes, with model (readily and slowly biodegradable) substrates and with real wastewaters.

Another important difference between the SBR and the CAS is the extent of nitrogen removal. If SBR processes are operated, as it is quite typical, with relatively low number of cycles per day and relatively short HRT, the extent of nitrogen removal is expected to be lower than in CAS processes. To increase nitrogen removal in SBR while maintaining a low HRT (which is desirable to reduce the capital cost of the plant), the number of cycles per day should be increased. This however could make the cycle length too short to leave enough time for the settling phase. A careful optimisation of the operating parameters, to be verified experimentally, is required to maximise nitrogen removal in SBR processes. Our analysis is based on the use of intrinsic kinetics and does not consider the effect of configuration design parameters, e.g. tank dimensions or type of mixing and aeration system, on the performance of the SBR and CAS processes. Configuration design parameters can affect the performance of biological processes, for example tank geometry and diffusers layout affect oxygen transfer in CAS processes (Karpinska and Bridgeman, 2016). However, our study assumes that processes are well designed, without any non-ideal mixing or mass transfer limitations, so that reactors can be modelled as perfectly mixed vessels and process performance is only determined by the microbial kinetics and by the SRT, HRT, internal recycle ratio and number of cycles per day.

It should be noted that the conclusions of this study depend on the mathematical model and on the kinetic parameters used. Alternative models are also possible. For example, while we assumed that endogenous metabolism converts microorganisms only to carbon 
dioxide and water, Bahar and Ciggin (2016), found that $25 \%$ of the biomass converted by endogenous metabolism is converted into inert suspended solids. Inclusion of inert formation from endogenous metabolism would have a small effect in the calculation of suspended solids by our models but wouldn't significantly change the results of our study. As far as nitrogen removal is concerned, we ignored any intermediates in ammonia oxidisation to nitrate and in nitrate reduction to molecular nitrogen. However, nitrogen oxides ( $\mathrm{N}_{2} \mathrm{O}$ and $\mathrm{NO}$ ) are intermediate in these processes and in some conditions can be released in the outlet gas stream (Domingo-Felez and Smets, 2020). Inclusion of the formation of these intermediates into our model would give a more accurate estimation of nitrogen removal but wouldn't change the comparison of nitrogen removal in CAS and SBR significantly. As far as the effect of the model parameters is concerned, the model parameters are expected to influence the extent of the observed differences between SBR and CAS processes, but not the general conclusions of this study. For example, Figure 10 shows the effect of changing the kinetic parameters Ks (Figure 10a) or b (Figure $10 b)$ on the effluent substrate concentration calculated for the SBR and CAS. Ks and b are the main parameters that affect the net rate of biomass growth and therefore the rate of substrate removal, and can vary in relatively large ranges (Dionisi, 2017). Figure 10 shows that the model result observed previously in Figure 3a, i.e. that the substrate is completely removed in the SBR while a residual effluent concentration is present in the CAS, is still valid even for a large variation of the parameters $\mathrm{Ks}$ and $\mathrm{b}$. While the extent of the effluent substrate concentration in the CAS depends on the values of Ks and b, complete removal is observed for the SBR for all the parameter values considered here. It is however important to use the results of this study to guide experimental work on the 
comparison of SBR and CAS. The experimental work will provide insight on which model describes the processes better and on the appropriate range for the model parameters. In this study, the calculations were carried out with Microsoft Excel, a general-purpose software. The same calculations can also be carried out with specialised software for the simulation of biological wastewater treatment processes. The differences between our approach and the modelling approach used in most specialised simulators have been discussed in our previous paper (Dionisi et al., 2016): a key difference is that our method allows the direct calculation of the SBR profiles at the periodic steady state without the need of the calculation of the process dynamics during start-up. However, any specialised commercial software can be used to select, design and optimise SBR and CAS processes according to the methodology and to the findings of the present study. 


\section{Conclusions}

Based on mathematical models of the processes, we have shown that the SBR has the advantage, over the CAS, to be able to achieve a complete degradation of the biodegradable COD. On the other hand, a residual concentration of biodegradable COD is predicted to be present in the effluent stream of the CAS, at higher concentration for a feed composed of slowly biodegradable substrates. For carbon removal processes, no significant differences between the SBR and the CAS are expected in oxygen consumption and sludge production, for the same operating parameters. In both processes, the net energy input can be minimised by optimising the SRT. For carbon and nitrogen removal processes, with typical values of the operating parameters, a higher nitrogen removal is expected in the CAS. For the SBR, nitrogen removal can be improved by increasing the HRT and/or increasing the number of cycles per day.

Overall, this study has identified the analogies and differences to be expected between CAS and SBR processes. All the main predictions of the model should be subject to experimental validation, as differences in process performance and in the magnitude of the expected effects could arise between simulations and real plants, due to uncertainties in the model structure and parameters and to the effect of configuration design parameters, which can cause non-ideal mixing and mass transfer limitations. It is expected that this analysis will stimulate experimental validation work and will be the basis for an informed choice of the type of process and for advanced process design. 


\section{References}

Andreottola, G., Foladori, P., Ragazzi, M. 2001. On-line control of a SBR system for nitrogen removal from industrial wastewater. Wat. Sci. Technol. 43(3), 93-100.

Artan, N., Wilderer, P., Orhon, D., Tasli, R., Morgenroth, E. 2002. Model evaluation and optimisation of nutrient removal potential for sequencing batch reactors. Water Sa, 28(4), 423-432.

Bahar, S., Ciggin, A. S. 2016. A simple kinetic modeling approach for aerobic stabilization of real waste activated sludge. Chem. Eng. J., 303, 194-201.

Carucci, A., Chiavola, A., Majone, M., \& Rolle, E. 1999. Treatment of tannery wastewater in a sequencing batch reactor. Wat. Sci. Technol. 40(1), 253.

Daverey, A., Pandey, D., Verma, P., Verma, S., Shah, V., Dutta, K., Arunachalam, K., 2019. Recent advances in energy efficient biological treatment of municipal wastewater. Biores. Technol. Rep. 7, 100252.

Dionisi, D., Rasheed, A. A., Majumder, A. 2016. A new method to calculate the periodic steady state of sequencing batch reactors for biological wastewater treatment: Model development and applications. J. Env. Chem. Eng. 4(3), 3665-3680.

Dionisi, D. 2017. Biological Wastewater Treatment Processes, 1st Edition. CRC Press, Boca Raton, FL, US.

Dockhorn, T., Dichtl, N., Kayser, R. 2001. Comparative investigations on COD-removal in sequencing batch reactors and continuous flow plants. Wat. Sci. Technol. 43(3), 4552.

Domingo-Felez, C., Smets, B. F. 2020. Modelling $\mathrm{N}_{2} \mathrm{O}$ dynamics of activated sludge biomass: Uncertainty analysis and pathway contributions. Chem. Eng. J., 379, 122311. 
Ge, H., Batstone, D. J., Mouiche, M., Hu, S., Keller, J. 2017. Nutrient removal and energy recovery from high-rate activated sludge processes-Impact of sludge age. Biores. Technol., 245, 1155-1161.

Henze, M., Gujer, W., Mino, T., van Loosdrecht, M.C. 2000. Activated sludge models ASM1, ASM2, ASM2d and ASM3. IWA publishing, London.

Henze, M., van Loosdrecht, M.C.M., Ekama, G.A., Brdjanovic, D. 2008. Biological wastewater treatment: principles, modelling and design. Iwapublishing, London.

Karpinska, A. M., Bridgeman, J. 2016. CFD-aided modelling of activated sludge systemsA critical review. Wat res $88,861-879$.

Klimiuk, E., Kulikowska, D. 2005. The influence of operational conditions in sequencing batch reactors on removal of nitrogen and organics from municipal landfill leachate. Was. Manag. Res. 23(5), 429-438.

McCarty, P. L., Bae, J., \& Kim, J., 2011. Domestic wastewater treatment as a net energy producer-can this be achieved?. Env. Sci. Technol. 45, 7100-7106.

Mirbagheri, S. A., SM, S. Y., Rafeidehkordi, N., Vakilian, R. 2017, August. Comparison of CAS, MBR, SBR, and Biolak Treatment Systems in Removal of BOD and COD from Municipal Wastewater-Case Study: Ekbatan Wastewater Treatment Plant. In 15th International Conference on Environmental Science and Technology, Rhodes, Greece. Vol. 31, pp. 1-5.

Mohan, S. V., Rao, N. C., Prasad, K. K., Madhavi, B. T. V., Sharma, P. N. 2005. Treatment of complex chemical wastewater in a sequencing batch reactor (SBR) with an aerobic suspended growth configuration. Proc. Biochem. 40(5), 1501-1508. 
Orhon, D., Çokgör, E. U., Sözen, S. 1999. Experimental basis for the hydrolysis of slowly biodegradable substrate in different wastewaters. Wat. Sci. Technol. 39(1), 87.

Papadimitriou, C. A., Samaras, P., Sakellaropoulos, G.P. 2009. Comparative study of phenol and cyanide containing wastewater in CSTR and SBR activated sludge reactors. Biores. Technol. 100(1), 31-37.

Sun, Y., Xin, L., Wu, G., Guan, Y., Sun, Y., Xin, L., Wu, G., Guan, Y. 2018. Nitrogen removal, nitrous oxide emission and microbial community in sequencing batch and continuous-flow intermittent aeration processes. Env. Eng. Res., 24(1), 107-116.

Teichgräber, B., Screff, D., Ekkerlein, C., Wilderer, P. A. 2001. SBR technology in Germany-an overview. Wat. Sci. Technol. 43(3), 323-330.

Yalmaz, G., Öztürk, I. 2001. Biological ammonia removal from anaerobically pre-treated landfill leachate in sequencing batch reactors (SBR). Wat. Sci. Technol. 43(3), 307-314. Wanner, J. (1992). Comparison of biocenoses from continuous and sequencing batch reactors. Wat. Sci. Technol. 25(6), 239-249. 
Table 1. Operating parameters for the base case of the simulations. For the simulations in which these values were changed, this is specified in the corresponding figures.

\begin{tabular}{|c|c|c|c|c|}
\hline Parameters & $\begin{array}{l}\text { CAS } \\
\text { carbon } \\
\text { removal }\end{array}$ & $\begin{array}{c}\text { CAS } \\
\text { carbon and } \\
\text { nitrogen } \\
\text { removal }\end{array}$ & $\begin{array}{c}\text { SBR } \\
\text { carbon } \\
\text { removal }\end{array}$ & $\begin{array}{c}\text { SBR } \\
\text { carbon and } \\
\text { nitrogen } \\
\text { removal }\end{array}$ \\
\hline $\mathrm{R}$, dimensionless & 1 & 1 & - & - \\
\hline $\mathrm{R}_{\mathrm{I}}$, dimensionless & - & 1 & - & - \\
\hline $\mathrm{HRT}_{1}, \mathrm{~d}$ & - & 0.15 & - & - \\
\hline $\mathrm{HRT}_{2}, \mathrm{~d}$ & - & 0.15 & - & - \\
\hline HRT, d & 0.3 & - & 0.3 & 0.3 \\
\hline No cycles, cycles/d & - & - & 4 & 4 \\
\hline$t_{\text {Aerfill, }} \min$ & - & - & 5 & - \\
\hline tAerreact, $\min$ & - & - & 290 & - \\
\hline tAnoxfill, $\min$ & - & - & - & 5 \\
\hline$t_{\text {Anoxreact, }} \min$ & - & - & - & 145 \\
\hline$t_{\text {Aerreact, }} \min$ & - & - & - & 145 \\
\hline$t_{w}, \min$ & - & - & 5 & 5 \\
\hline$t_{s e t t l e, ~} \min$ & - & - & 45 & 45 \\
\hline teff, $\min$ & - & - & 15 & 15 \\
\hline $\mathrm{t}_{\text {cycle, }}, \min$ & - & - & 360 & 360 \\
\hline
\end{tabular}


Table 2. Kinetic parameters used in this study (CAS and SBR).

\begin{tabular}{|c|c|c|c|}
\hline \multirow[b]{2}{*}{ Parameters } & \multicolumn{2}{|c|}{ Carbon removal } & \multirow{2}{*}{$\begin{array}{c}\text { Carbon and } \\
\text { Nitrogen removal } \\
\text { Readily } \\
\text { biodegradable } \\
\text { feed }\end{array}$} \\
\hline & $\begin{array}{c}\text { Readily } \\
\text { biodegradable } \\
\text { feed }\end{array}$ & $\begin{array}{c}\text { Slowly } \\
\text { biodegradable } \\
\text { feed }\end{array}$ & \\
\hline$\mu_{\max }, \mathrm{d}^{-1}$ & 6 & 6 & 6 \\
\hline$\mu_{\max A,} d^{-1}$ & - & - & 4 \\
\hline$b, d^{-1}$ & 0.1 & 0.1 & 0.1 \\
\hline$b_{A}, d^{-1}$ & - & - & 0.1 \\
\hline $\mathrm{Ks}, \mathrm{kg} \mathrm{COD} / \mathrm{m}^{3}$ & 0.005 & 0.005 & 0.005 \\
\hline $\mathrm{kh}, \mathrm{kg} \mathrm{COD} / \mathrm{kg} / \mathrm{d}$ & - & 3.0 & - \\
\hline $\mathrm{Kx}, \mathrm{kg} \mathrm{COD} / \mathrm{kg}$ & - & 0.02 & - \\
\hline $\mathrm{KsNO}_{3}, \mathrm{~kg} \mathrm{~N}-\mathrm{NO}_{3} / \mathrm{m}^{3}$ & - & - & 0.003 \\
\hline $\mathrm{KsNH}_{3}, \mathrm{~kg} \mathrm{~N}-\mathrm{NH}_{3} / \mathrm{m}^{3}$ & - & - & 0.003 \\
\hline$Y_{X / S}, \mathrm{~kg} / \mathrm{kg}$ COD & 0.3 & 0.3 & 0.3 \\
\hline $\mathrm{YXA}_{\mathrm{X} / \mathrm{NO}}, \mathrm{kg} / \mathrm{kg} \mathrm{N}-\mathrm{NO}_{3}$ & - & - & 0.1 \\
\hline $\mathrm{S}_{0}, \mathrm{~kg} \mathrm{COD} / \mathrm{m}^{3}$ & 0.5 & 0.5 & - \\
\hline$X_{s o}, \mathrm{~kg} \operatorname{COD} / \mathrm{m}^{3}$ & - & - & 0.5 \\
\hline $\mathrm{NH}_{30}, \mathrm{~kg} \mathrm{~N}-\mathrm{NH}_{3} / \mathrm{m}^{3}$ & - & - & 0.06 \\
\hline
\end{tabular}



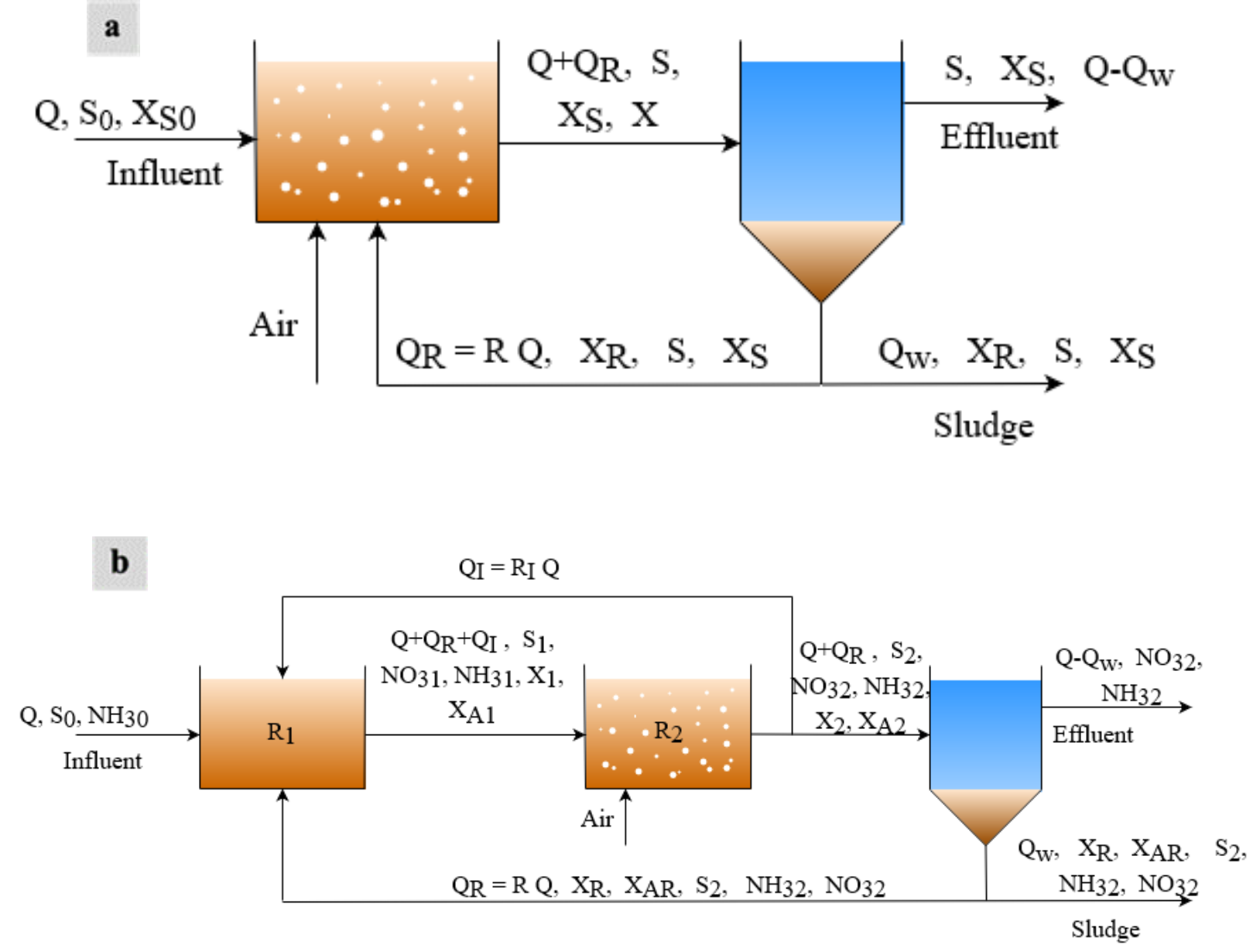

Figure 1. Configurations of the CAS: (a) Carbon removal; (b) Carbon and nitrogen removal. 

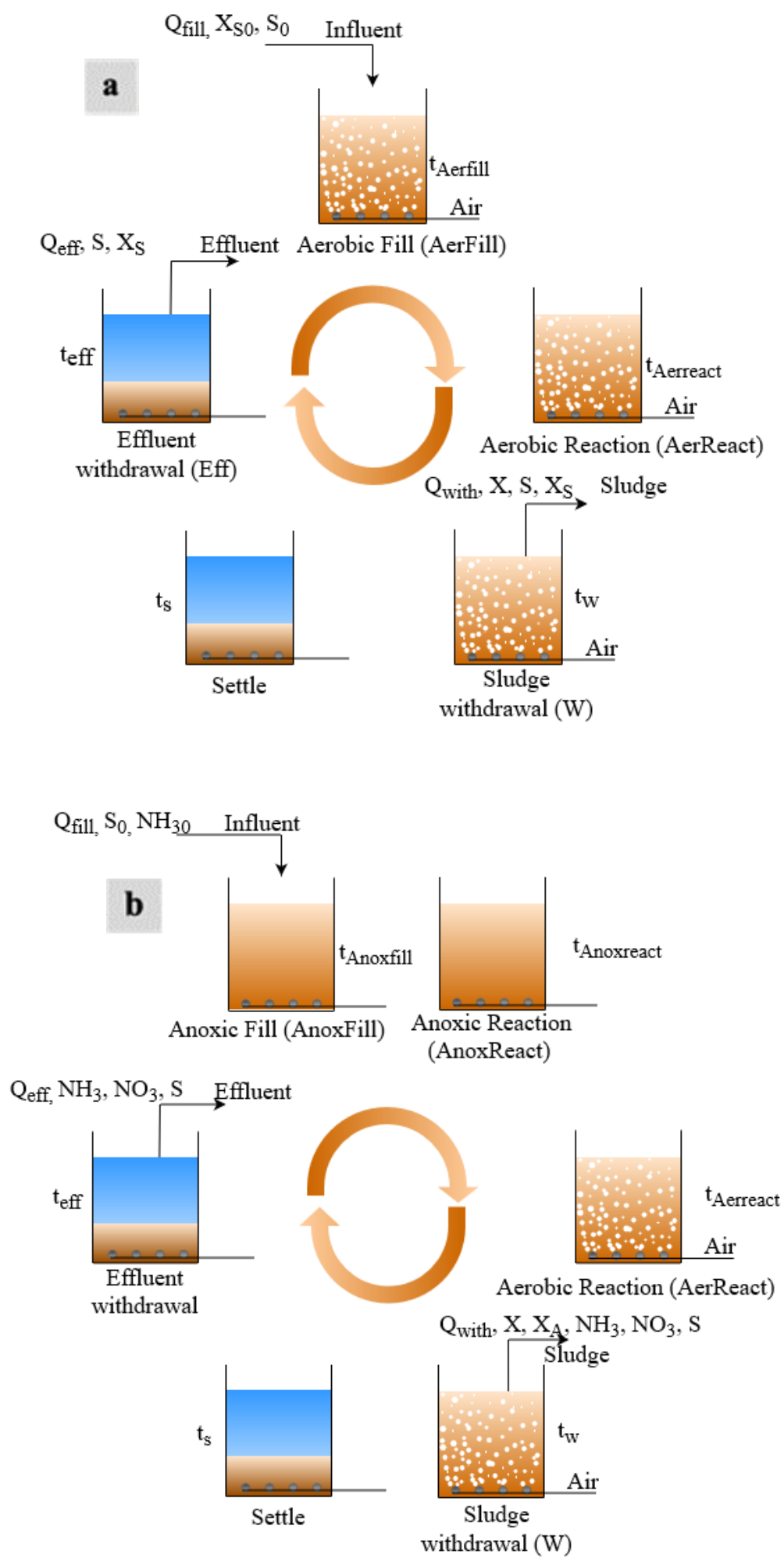

Figure 2. Configuration of the SBR: (a) Carbon removal; (b) Carbon and nitrogen removal. 

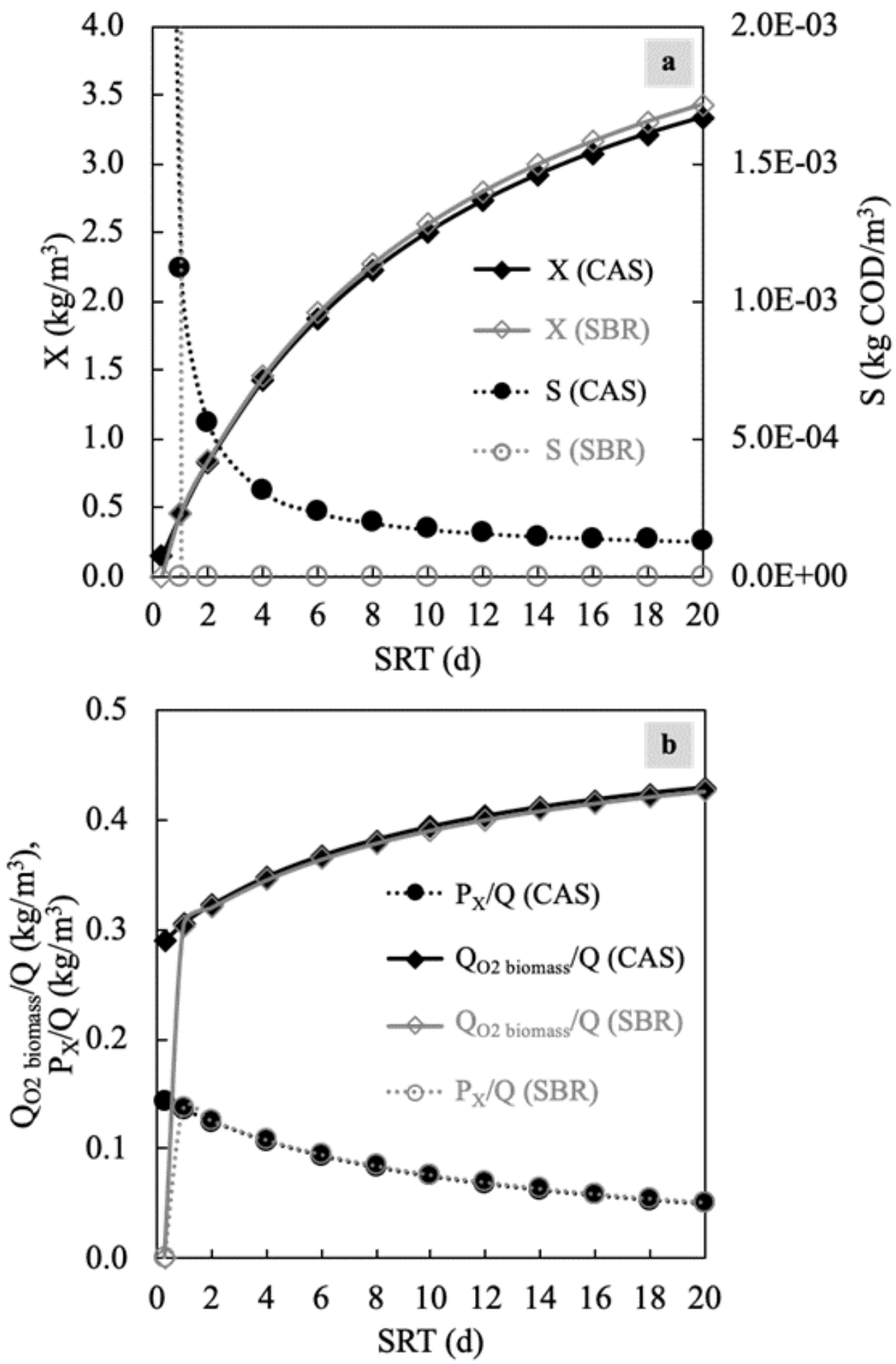

Figure 3. Effect of the SRT on (a) biomass (X) and substrate (S) concentrations and on (b) oxygen consumption (Qozbiomass/Q) and sludge production (Px/Q). Readily biodegradable substrate in the influent. 


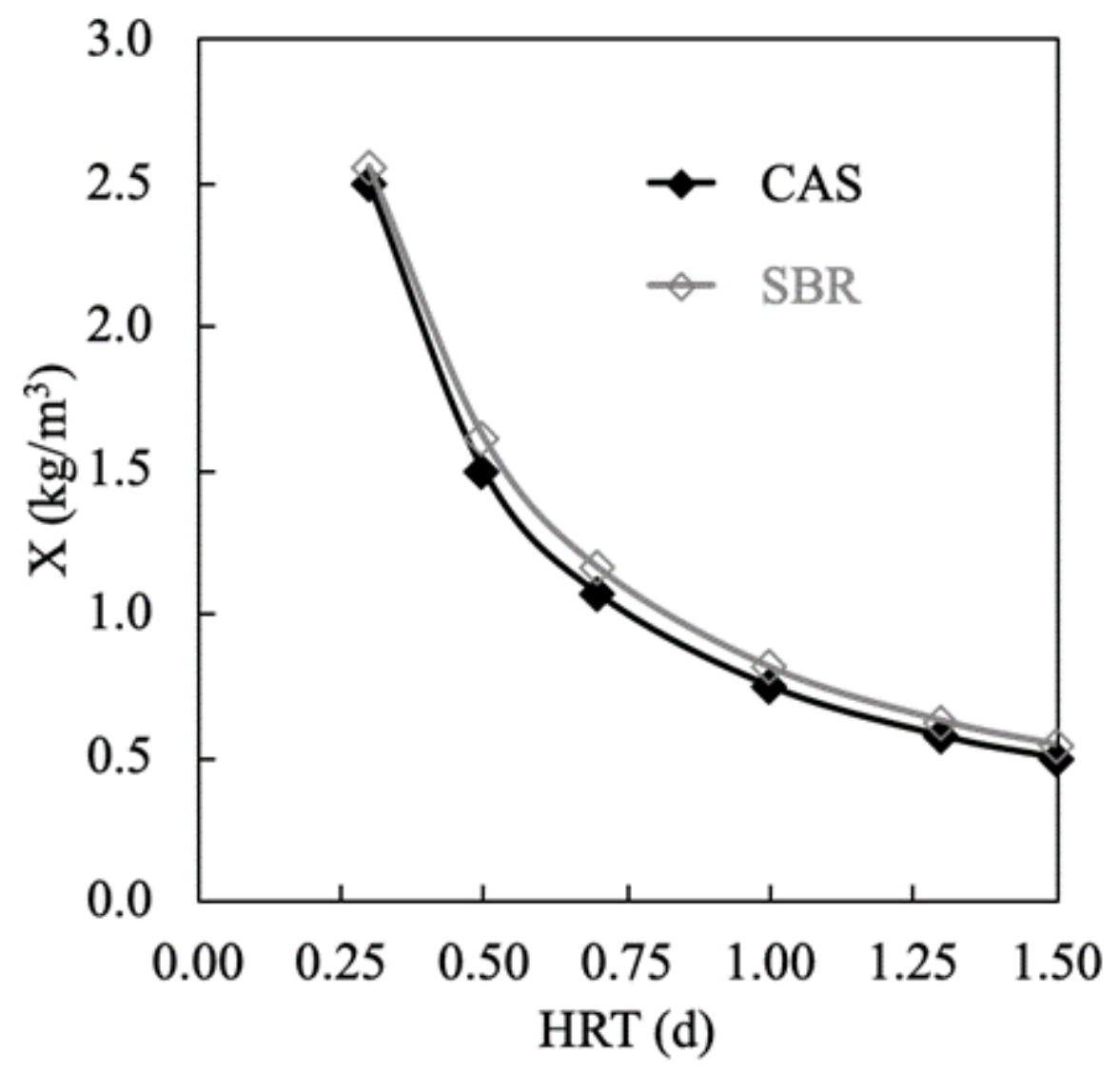

Figure 4. Effect of the HRT on the biomass concentration (X). Readily biodegradable substrate in the influent. SRT $10 \mathrm{~d}$. 


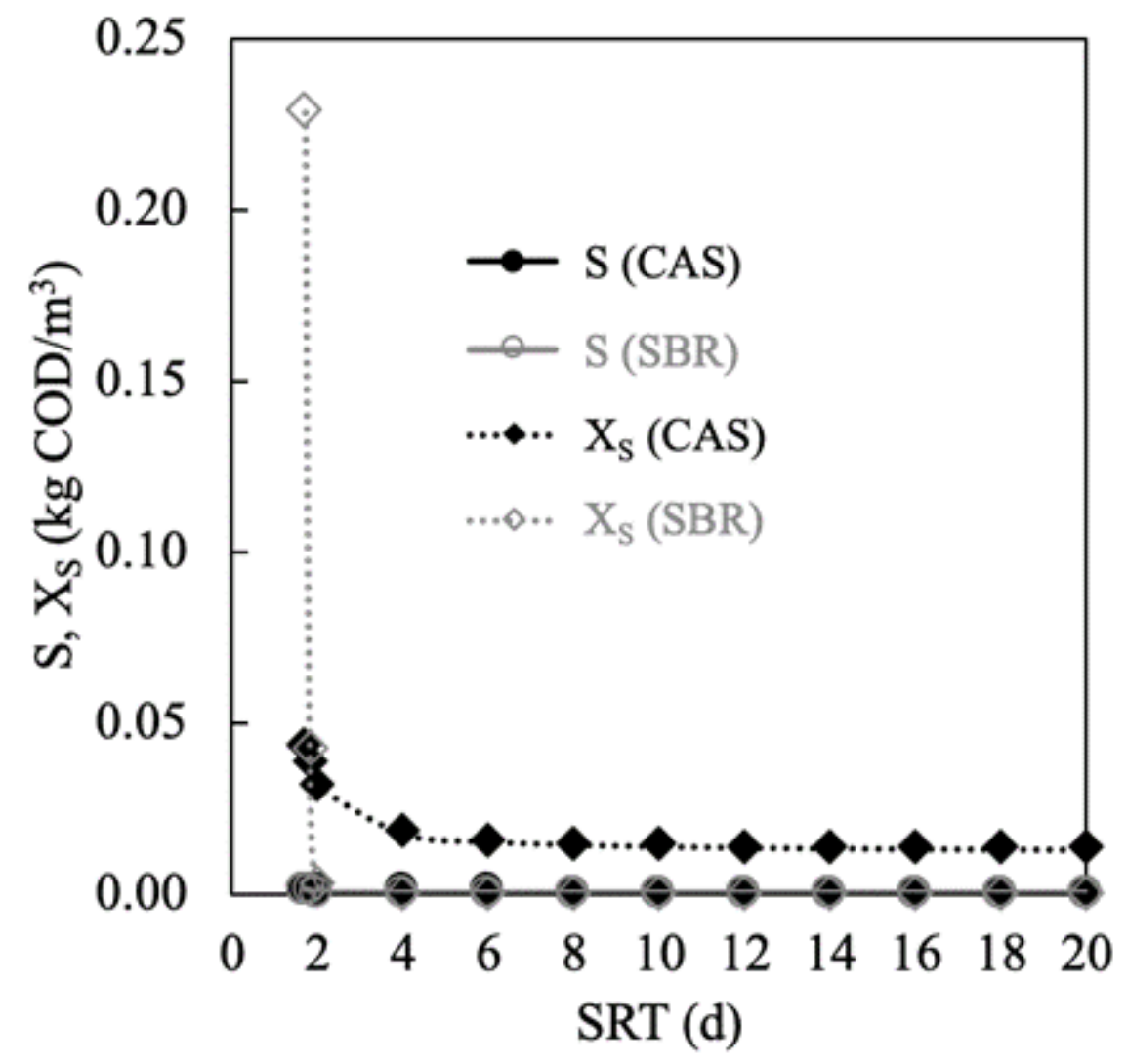

Figure 5. Effect of the SRT on the slowly (Xs) and readily (S) biodegradable substrate concentrations. Slowly biodegradable substrate in the influent. 

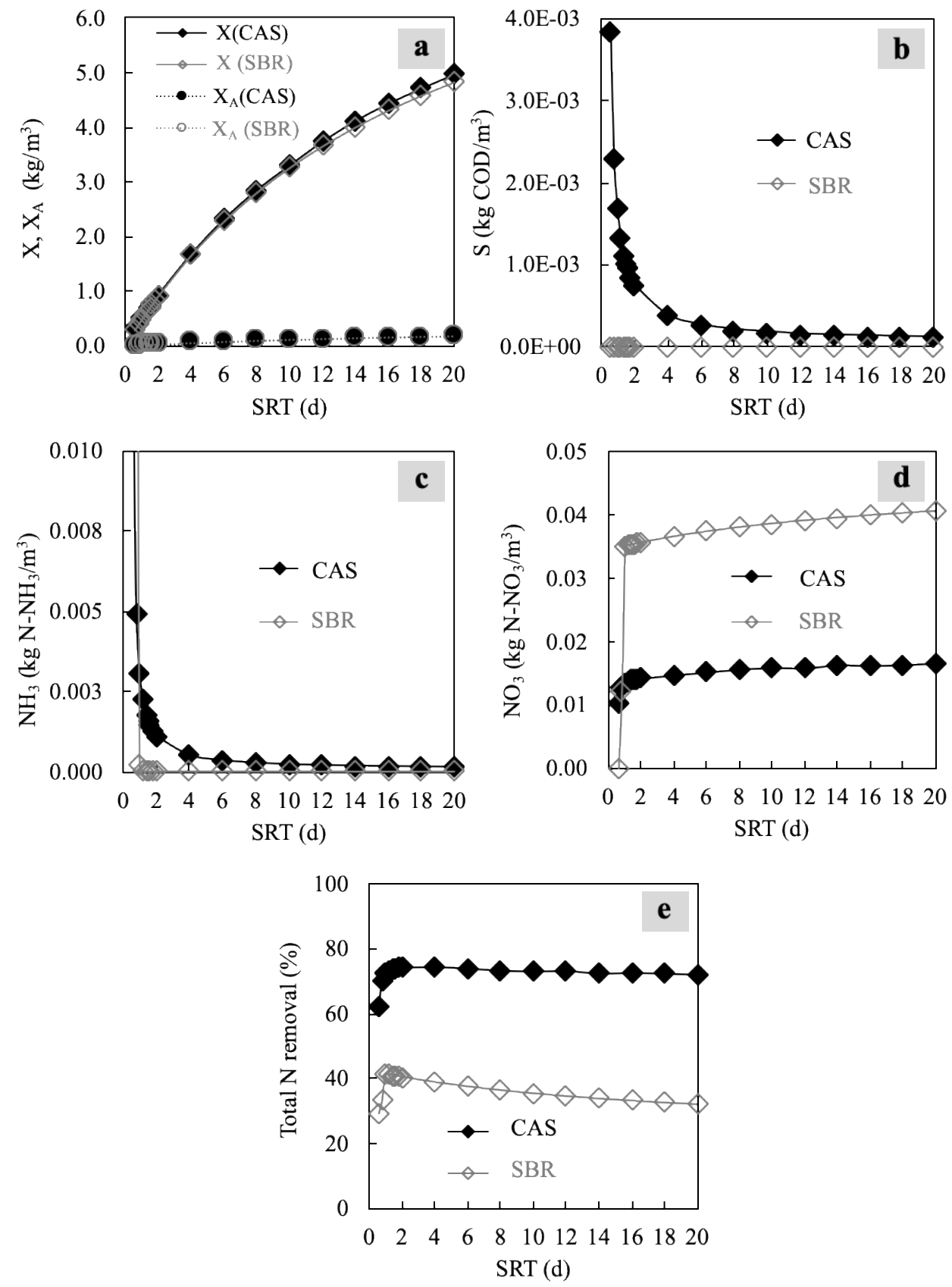

Figure 6. Effect of the SRT on the concentrations of (a) heterotrophic $(X)$ and autotrophic $\left(\mathrm{X}_{\mathrm{A}}\right)$ biomass, (b) substrate $(\mathrm{S})$, (c) ammonia $\left(\mathrm{NH}_{3}\right)$, and (d) nitrate $\left(\mathrm{NO}_{3}\right)$ along with the effect on the (e) percentage of total nitrogen removed. 

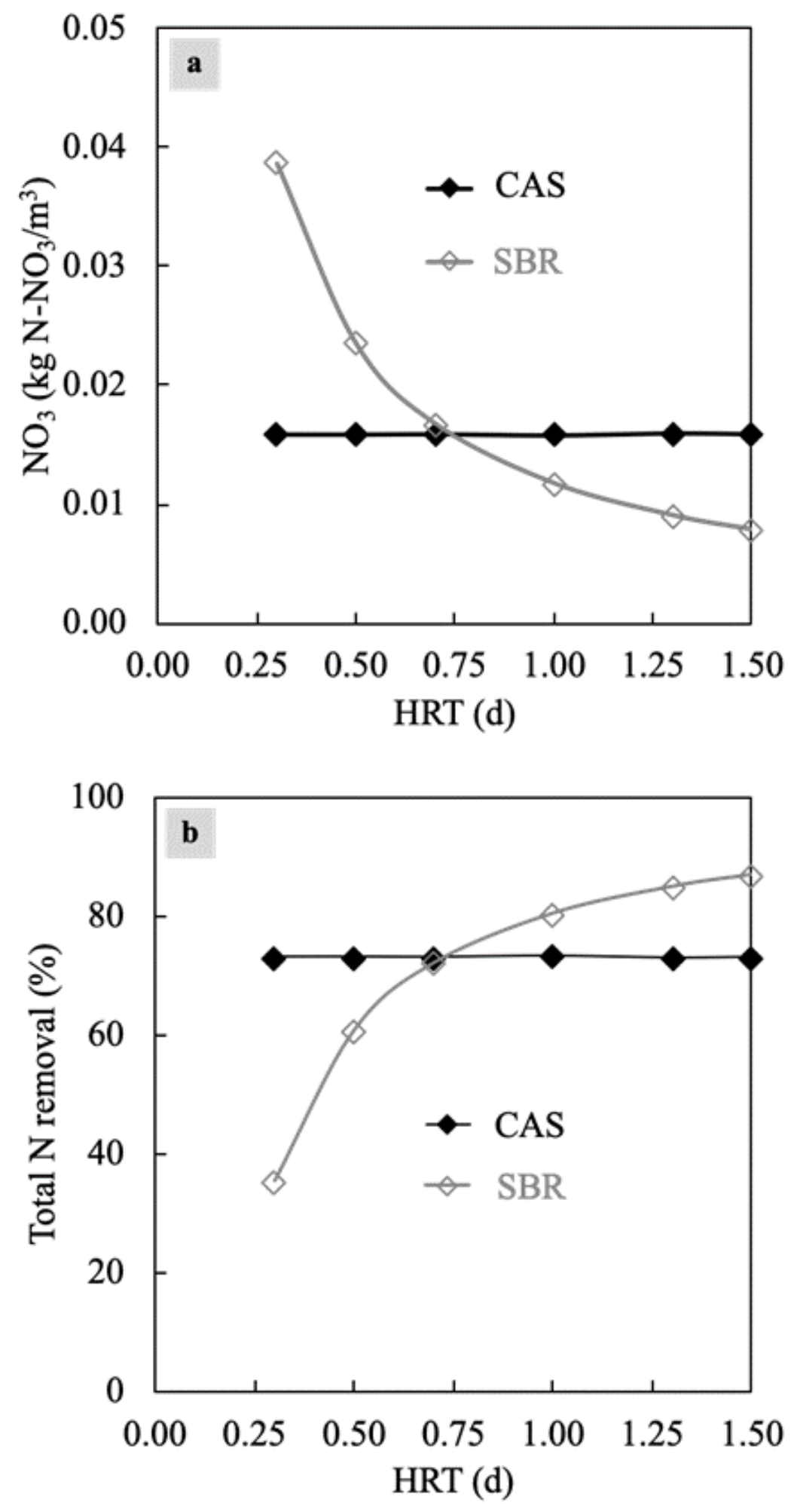

Figure 7. Effect of the HRT on the (a) concentration of nitrate $\left(\mathrm{NO}_{3}\right)$ and on the $(b)$ percentage of total nitrogen removed. SRT $10 \mathrm{~d}$. 

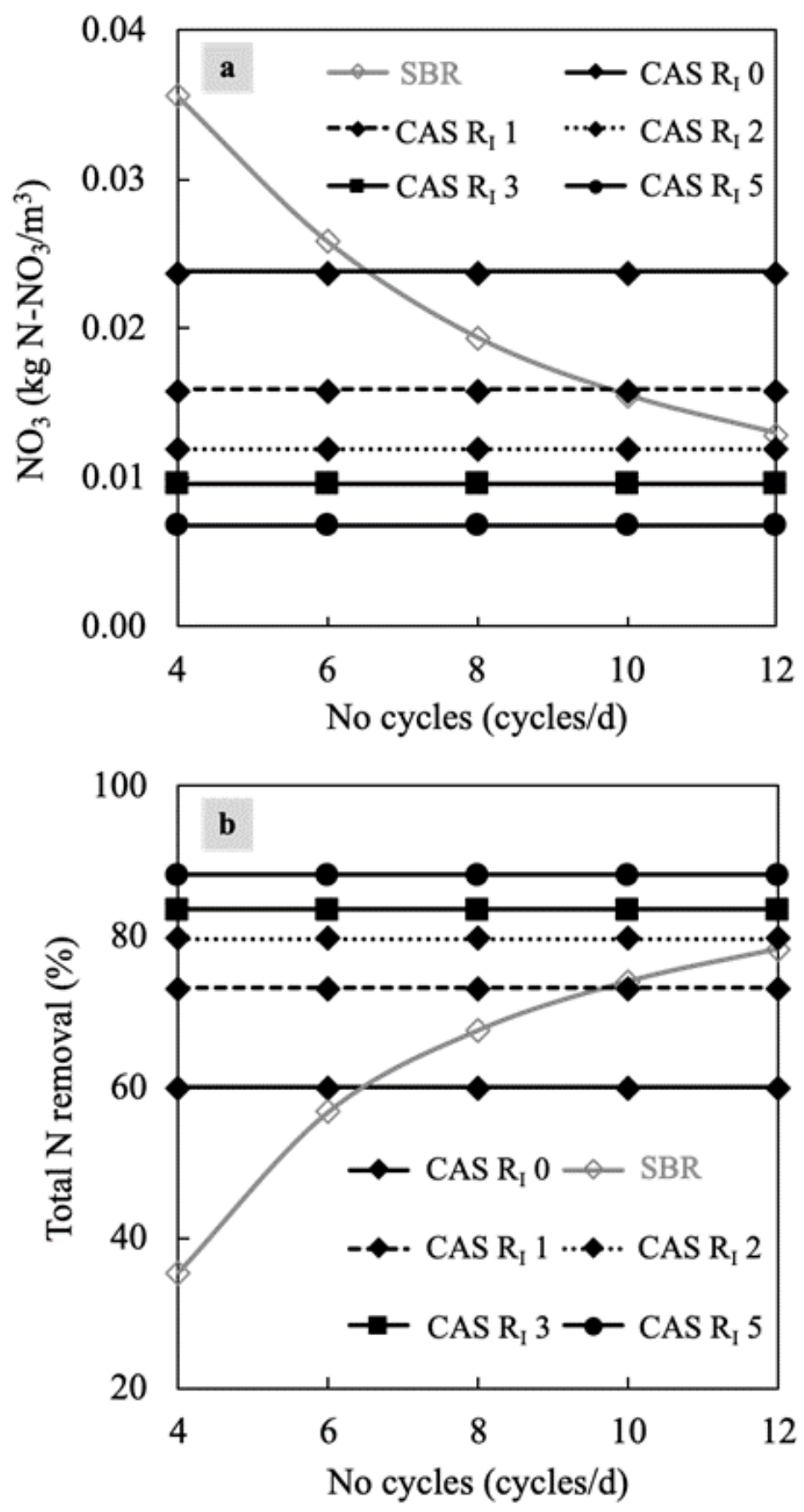

Figure 8. Effect of the number of cycles (No cycles) and the internal recycling rate $\left(\mathrm{R}_{\mathrm{I}}\right)$ on the (a) nitrate concentration $\left(\mathrm{NO}_{3}\right)$ and on the (b) percentage of total nitrogen removed. SRT $10 \mathrm{~d}$. In the SBR, changing the number of cycles per day was obtained by changing the length of all phases in the same proportion. 


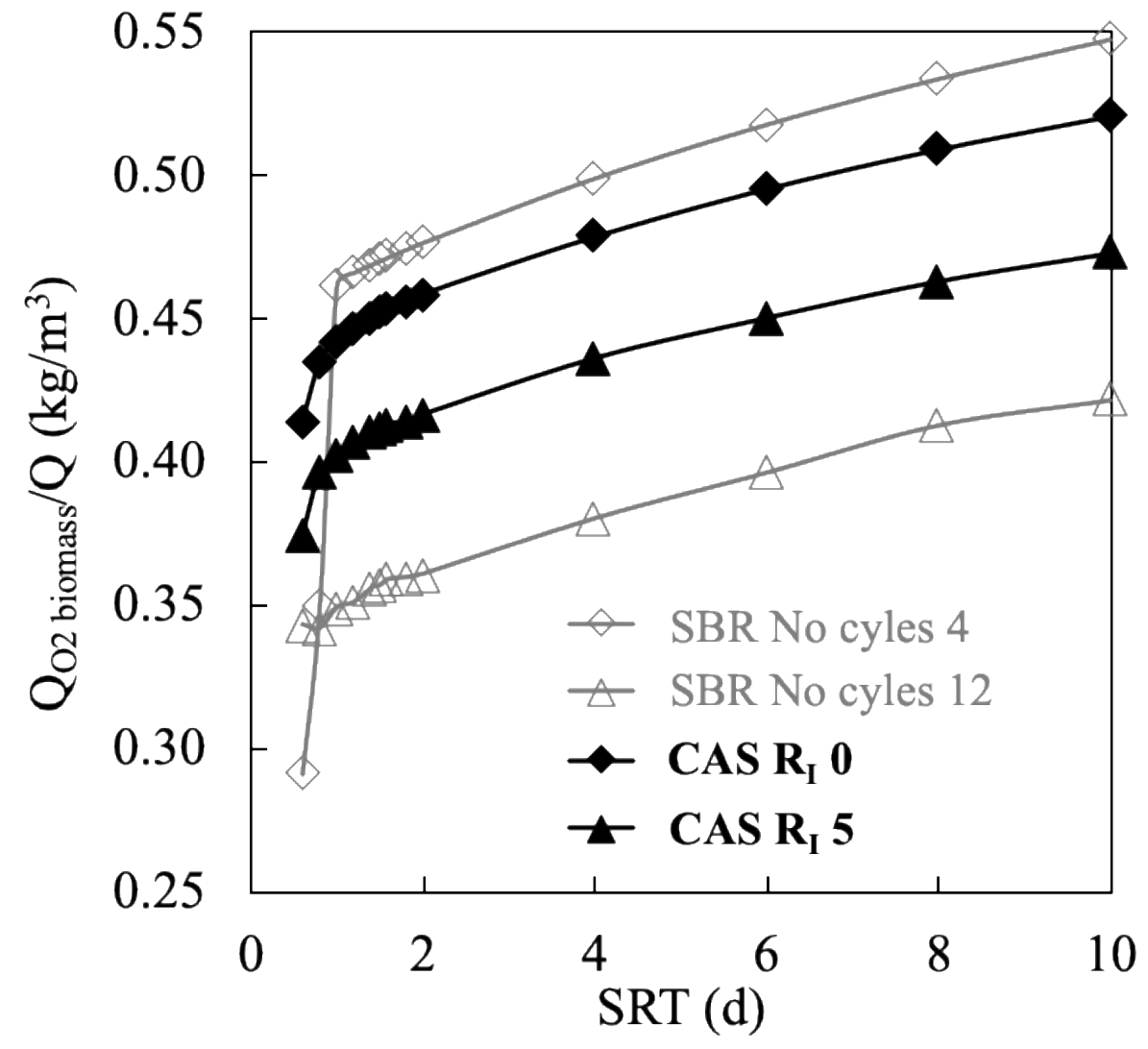

Figure 9. Oxygen consumption for the SBR and CAS for carbon and nitrogen removal. 

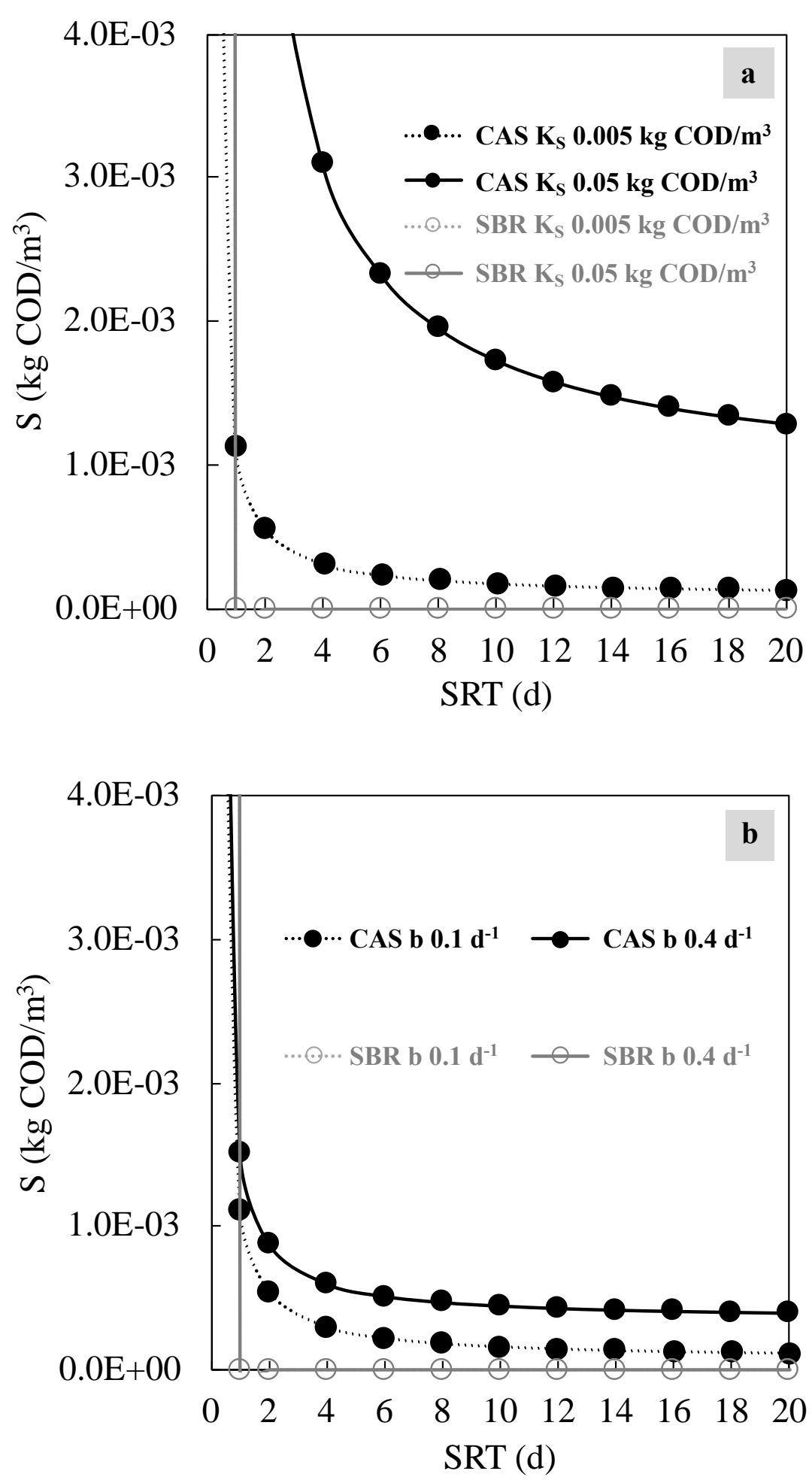

Figure 10. Effect of the value of the kinetic parameters (carbon removal, readily biodegradable feed). a) Effect of $\mathrm{Ks}_{\mathrm{s}}$ (parameter in the Monod rate equation); b) effect of $\mathrm{b}$ (parameter in the endogenous metabolism rate equation). Other parameters have the values in Table 2. 